\title{
Numerical simulations of homogeneous freezing processes in the aerosol chamber AIDA
}

\author{
W. Haag ${ }^{1}$, B. Kärcher ${ }^{1}$, S. Schaefers ${ }^{2}$, O. Stetzer ${ }^{2}$, O. Möhler ${ }^{2}$, U. Schurath ${ }^{2}$, M. Krämer ${ }^{3}$, and C. Schiller ${ }^{3}$ \\ ${ }^{1}$ Deutsches Zentrum für Luft- und Raumfahrt (DLR), Institut für Physik der Atmosphäre (IPA), Oberpfaffenhofen, Germany \\ ${ }^{2}$ Forschungszentrum Karlsruhe (FZK), Institut für Meteorologie und Klimaforschung (IMK-3), Karlsruhe, Germany \\ ${ }^{3}$ Forschungszentrum Jülich (FZJ), Institut für Chemie und Dynamik der Geosphäre (ICG-1), Jülich, Germany
}

Received: 26 August 2002 - Published in Atmos. Chem. Phys. Discuss.: 7 October 2002

Revised: 16 December 2002 - Accepted: 14 January 2003 - Published: 20 February 2003

\begin{abstract}
The homogeneous freezing of supercooled $\mathrm{H}_{2} \mathrm{SO}_{4} / \mathrm{H}_{2} \mathrm{O}$ aerosols in an aerosol chamber is investigated with a microphysical box model using the activity parameterization of the nucleation rate by Koop et al. (2000). The simulations are constrained by measurements of pressure, temperature, total water mixing ratio, and the initial aerosol size distribution, described in a companion paper (Möhler et al., 2003). Model results are compared to measurements conducted in the temperature range between 194 and $235 \mathrm{~K}$, with cooling rates in the range between 0.5 and $2.6 \mathrm{~K} \mathrm{~min}^{-1}$, and at air pressures between 170 and $1000 \mathrm{hPa}$. The simulations focus on the time history of relative humidity with respect to ice, aerosol size distribution, partitioning of water between gas and particle phase, onset times of freezing, freezing threshold relative humidities, aerosol chemical composition at the onset of freezing, and the number of nucleated ice crystals. The latter four parameters can be inferred from the experiments, the former three aid in interpreting the measurements. Sensitivity studies are carried out to address the relative importance of uncertainties of basic quantities such as temperature, total $\mathrm{H}_{2} \mathrm{O}$ mixing ratio, aerosol size spectrum, and deposition coefficient of $\mathrm{H}_{2} \mathrm{O}$ molecules on ice. The ability of the numerical simulations to provide detailed explanations of the observations greatly increases confidence in attempts to model this process under real atmospheric conditions, for instance with regard to the formation of cirrus clouds or polar stratospheric ice clouds, provided that accurate temperature and humidity measurements are available.
\end{abstract}

\section{Introduction}

Although it remains a subject of debate under which atmospheric conditions homogeneous freezing of supercooled aerosols leads to the formation of cirrus clouds, the relevance

Correspondence to: W. Haag (Werner.Haag@dlr.de) of this process has been emphasized in many previous studies (Heymsfield and Sabin, 1989; Sassen and Dodd, 1989; Jensen and Toon, 1992; Heymsfield and Miloshevich, 1993; Jensen et al., 1998; Lin et al., 1998; Field et al., 2001). It has been shown that the special class of orographic ice clouds predominantly forms at large supersaturations with respect to ice at temperatures below the spontaneous freezing point of pure water $(\sim 235 \mathrm{~K})$, and it seems likely that homogeneous freezing of supercooled solutions is the dominant ice particle formation mechanism for this cloud type, given the large cooling rates of air parcels induced by atmospheric waves. It has been demonstrated that one way to form polar stratospheric ice clouds occurs via homogeneous freezing of diluted supercooled aerosols composed of $\mathrm{H}_{2} \mathrm{O}, \mathrm{H}_{2} \mathrm{SO}_{4}$, and $\mathrm{HNO}_{3}$ (Carslaw et al., 1997), although other formation pathways may exist (Peter, 1997).

The homogeneous nucleation rates used in previous numerical simulations of cirrus formation were subject to significant changes over the last decade (Jensen and Toon, 1991; Tabazadeh et al., 1997, 2000), with a tendency to predict higher freezing threshold relative humidities when more recent laboratory results were used to derive the rates (Koop et al., 1998; Chang et al., 1999; Koop et al., 1999; Bertram et al., 2000; Chen et al., 2000). Recently, it has been shown that the threshold relative humidities for homogeneous freezing of chemically different supercooled droplets in the $\mu \mathrm{m}$ size range are almost similar, provided the freezing droplets (which may contain different types and amounts of solutes) have the same water activity at a given temperature (Koop et al., 2000).

In this work, we present a comprehensive comparison of results from ice nucleation experiments carried out in the aerosol chamber AIDA (Aerosol Interaction and Dynamics in the Atmosphere) of Forschungszentrum Karlsruhe with microphysical simulations of the ice initiation process and the initial growth phase of the ice particles using the APSC (Advanced Particle Simulation Code) developed at

(C) European Geosciences Union 2003 

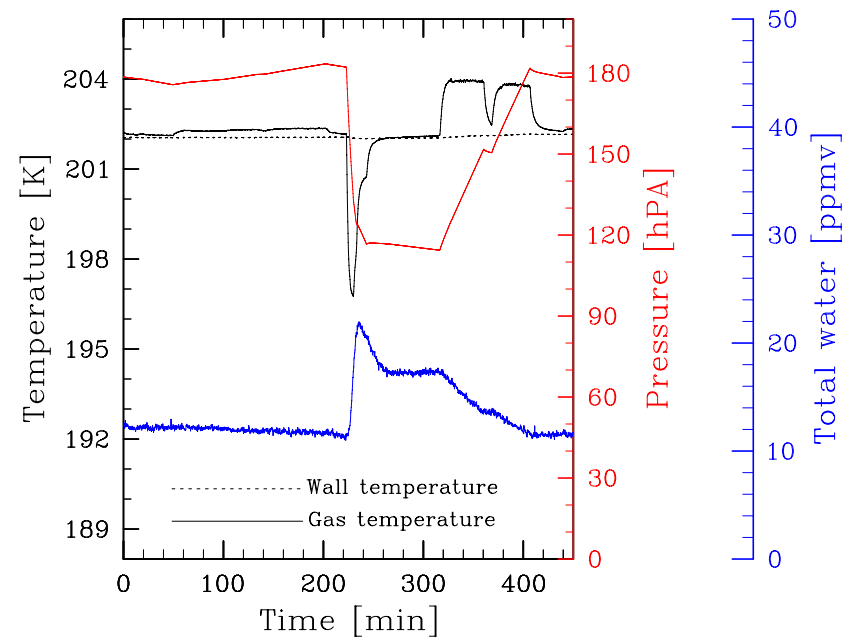

Fig. 1. Variation of pressure, gas and wall temperature, and total water inside the AIDA chamber during a typical freezing experiment. The time scale starts with the generation of binary $\mathrm{H}_{2} \mathrm{SO}_{4} / \mathrm{H}_{2} \mathrm{O}$ aerosol. In the period from $220 \mathrm{~min}$ to $240 \mathrm{~min}$ the fast pressure drop leads to a rapid decrease of the gas temperature, a strong supersaturation with respect to ice, and the initiation of spontaneous freezing of the supercooled aerosols by homogeneous ice nucleation. The variation of total water indicates that $\mathrm{H}_{2} \mathrm{O}$ interacts with the chamber walls.

Deutsches Zentrum für Luft- und Raumfahrt (DLR). The measurements are described in detail in a companion paper (Möhler et al., 2003), but we recall some features relevant to the comparison, for convenience. The simulations use the activity-based parameterization of the homogeneous nucleation rate developed by Koop et al. (2000).

Despite some effects introduced by the large but finite measuring volume, of which special care has to be taken in the model, the AIDA approach to simulate ice formation has a great advantage over airborne measurements: important quantities such as the total water mixing ratio and temperature are obtained with high precision in one volume of air where the phase transition actually takes place. This provides tight constraints for the numerical calculations.

In the field, it is very difficult to perform Lagrangian-type flights to be able to describe cloud formation in a similar manner, even in quasi-stationary wave clouds. Thus, in many cases, the resulting uncertainties in the computed relative humidities and other variables render definite conclusions about the nature of the underlying nucleation processes impossible. In other laboratory studies of ice formation, it is very difficult to prepare realistic polydisperse aerosols and dynamical environments, and many experiments have been carried out using constant temperatures and monodisperse, super $\mu \mathrm{m}$-sized droplets. In the AIDA chamber, the number and size distributions of aerosol particles, relative humidities, temperatures, and pressures are typical for the upper troposphere and lower stratosphere; the cooling rates are typical for strong wave or convective activity. Thus these measurements very closely mimick real atmospheric conditions prevailing in cirrus or polar stratospheric ice clouds.

\section{Experiments}

Figure 1 depicts the overall evolution of the temperature $T$ (black solid curve) and pressure $p$ (red curve) in the chamber volume, the wall temperature (black dotted curve), and the total water volume mixing ratio $q$ (blue curve) taken during a typical freezing experiment. The latter is measured in an ex-situ mode with the Lyman- $\alpha$ hygrometer of the Forschungszentrum Jülich (Fast In situ Stratospheric Hygrometer, FISH). For a more detailed description of the $\mathrm{H}_{2} \mathrm{O}$ measurements in the AIDA chamber, we refer to the companion paper (Möhler et al., 2003). The FISH instrument demonstrated its reliability to accurately measure low $\mathrm{H}_{2} \mathrm{O}$ concentrations (in the ppm-range) in numerous airborne campaigns (Zöger et al., 1999).

The freezing experiments in the AIDA chamber start at homogeneous temperature and relative humidity conditions. The initial relative humidity with respect to ice (RHI) is close to ice saturation, established by coating the chamber walls with water ice before each experiment. Before cooling, a slight offset of $0.1-0.2 \mathrm{~K}$ is observed in Fig. 1 between the mean temperature $T$ of the gas in the chamber volume and the mean wall temperature (Möhler et al., 2003).

Sulfuric acid particles are added to the chamber at a constant pressure. They quickly equilibrate with the available water vapor, forming liquid $\mathrm{H}_{2} \mathrm{SO}_{4} / \mathrm{H}_{2} \mathrm{O}$ solution droplets. In the first 3 hours, $T, p$, and $q$ remain relatively constant and the aerosol size distribution is slightly modified by Brownian coagulation and wall deposition processes. After $220 \mathrm{~min}$ the chamber is cooled by volume expansion via controlled pumping. Cooling is adiabatic only in the very first stage of the evacuation phase (Möhler et al., 2003). During this evacuation of the vessel, $T$ drops several degrees below the wall temperature, which remains constant due to the very large heat capacity of the alumimium vessel walls; see Fig. 1. As will be discussed below, the expansion-cooling allows to achieve high supersaturations with respect to ice, sufficient to induce homogeneous freezing in the strongly supercooled $\mathrm{H}_{2} \mathrm{SO}_{4} / \mathrm{H}_{2} \mathrm{O}$ aerosol.

When the pumping is stopped at $240 \mathrm{~min}, T$ starts to rise driven by the heat flux from the (warmer) chamber walls until it becomes equal to the wall temperature, indicating that the chamber returns to a thermodynamic equilibrium, as depicted in Fig. 1. Refilling the chamber with dry synthetic air at $320 \mathrm{~min}$ leads to a transient warming of the gas. Under nearly constant pressure conditions after $400 \mathrm{~min}$, the chamber equilibrates again.

The FISH measurements show an increase of the $\mathrm{H}_{2} \mathrm{O}$ mixing ratio $q$ during the initial rapid cooling phase. This is a result of a net flux of water vapor from the ice-coated 
chamber walls into the cooler gas. The molecular flux of $\mathrm{H}_{2} \mathrm{O}$ is associated with the heat flux discussed above. During the cooling phase, ice particles are formed from the aerosol, as discussed in Sects. 4 and 5.

The decrease of $q$ after the cooling phase may be caused by sedimentation of large ice particles, by wall impaction, or by inefficient sampling by the FISH inlet (the diameter below which the particle sampling efficiency is near $100 \%$ is $\sim 7 \mu \mathrm{m}$ ). It is currently not possible to estimate the relative importance of these processes in reducing $q$ on the basis of the measurements. Using a simplified parameterization of the apparent loss of total water, we will return to this issue in more detail in Sect. 4.3.

\section{Modeling}

We employ the DLR aerosol/cloud trajectory model APSC, with modules treating the microphysical processes involved in the AIDA experiments. Results of this model obtained during phase 1 of the Global Energy and Water Cycle Experiment (GEWEX) cirrus parcel model intercomparison project are discussed in Lin et al. (2002) and Kärcher and Lohmann (2002). A description of the model physics relevant to the present studies is given below.

We constrain the simulations by prescribing the initial aerosol size distribution and the measured temporal evolution of temperature, pressure and total water mixing ratio, similar to the case study depicted in Fig. 2. Recall that the expansion cooling becomes non-adiabatic shortly after the onset of pumping. The model solves the equations governing condensational growth of the liquid particles and depositional growth of ice particles by uptake of water vapor. The physical processes are treated kinetically over a moving center size structure (Jacobson, 1999). In the moving center size structure, size-bin edges are fixed, but the particles are allowed to grow or evaporate to their exact sizes. If the average volume of a particle in a bin grows larger than the high-edge volume of the bin, all particles in the bin are moved to a single bin bounding the new average volume. This scheme is almost free of numerical diffusion, because all particles are moved to the same size bin and are not partitioned amongst two or more size bins.

Aerosol and ice particles are treated as separate particle types. The aerosol and ice particle size distrubutions are discretized over 80 size bins with a constant bin-volume ratio of 1.6 , starting at a minimum particle radius of $1 \mathrm{~nm}$. The constant time step chosen is $\Delta t=0.1 \mathrm{~s}$, sufficiently small to yield accurate numerical solutions. The initial size distribution of the aerosol particles is lognormal, with dry $\mathrm{H}_{2} \mathrm{SO}_{4}$ mass, mean mass radius, and geometric standard deviation $\sigma$ as input parameters. As we are only interested in the growth of freshly nucleated, small (up to several $\mu \mathrm{m}$ ) ice particles, the assumption of a spherical shape is reasonable.

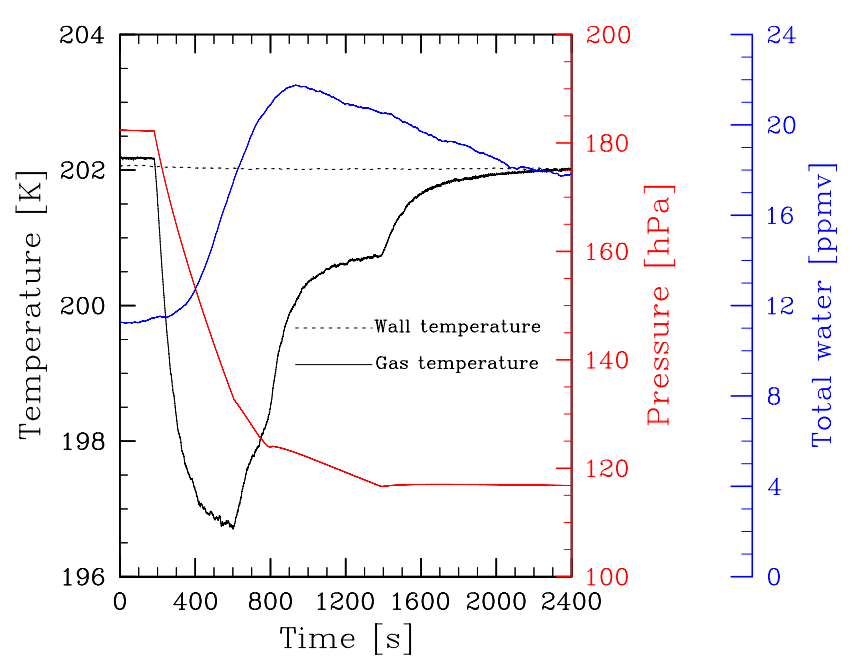

Fig. 2. Modeled cooling period of the case study starting at $T=$ $202 \mathrm{~K}, p=180 \mathrm{hPa}$, and $q=11 \mathrm{ppmv}$. The wall temperature (dotted curve) varies only slightly. These curves are extracted from Fig. 1 by converting the time units from min to $s$ and by shifting the time axis; pumping now starts after $180 \mathrm{~s}$.

Growth and evaporation of aerosols are treated using the analytical predictor of dissolution (APD) scheme introduced by Jacobson (1999). This scheme is non-interative, unconditionally stable, mass-conserving, and fully coupled to the gas phase. In the APD scheme, the size-resolved mass concentrations of all chemical components in the aerosol particles and their respective concentrations in the gas phase are tracked as a function of time. (In the current simulation, only $\mathrm{H}_{2} \mathrm{O}$ is allowed to change.) A measure of the mass concentration is the mass fraction, that is the mass of a given species in a particle divided by the total particle mass. Note that the $\mathrm{H}_{2} \mathrm{SO}_{4}$ mass fraction $W$ in an aerosol particle depends on the particle size due to the Kelvin effect. The bulk phase vapor pressure of water is taken from Luo et al. (1995). The Kelvin term enhances this pressure significantly for particles with radii below about $0.05 \mu \mathrm{m}$. Coagulation processes are switched off in the simulations, as they are too slow to affect the freezing process and the growth of the pristine ice particles. (This cooling and growth phase lasts only about 30 min.) We define a constant loss of liquid $\mathrm{H}_{2} \mathrm{SO}_{4} / \mathrm{H}_{2} \mathrm{O}$ particles in the simulations, corresponding to the observed decrease of the total number concentration of aerosol particles at constant pressure conditions in the AIDA chamber due to particle sedimentation and diffusional losses to the chamber walls.

With regard to freezing, we use the homogeneous nucleation rates $J$ measured and parameterized by Koop et al. (2000). In this formulation, $J$ depends only on $T$ and on the water activity $a(W, T)$ of the aerosol particles, which, in turn, is size-dependent. The principal features of cirrus formation driven by adiabatic cooling based on these measurements have been discussed elsewhere (Kärcher, 2002; Lin 
et al., 2002). At each time step and in each size bin, we calculate the nucleation time scale $t_{\text {nuc }}=1 /(V J)$, where $V$ is the particle volume, and compare it with the time step $\Delta t$. The fraction of freezing aerosol particles in each time step is thus proportional to $\exp \left(-\Delta t / t_{\text {nuc }}\right)$. This method allows partial freezing in each aerosol size bin and conserves the total mass of each chemical species.

Growth and evaporation of ice crystals are treated using the analytical predictor of condensation (APC) scheme introduced by Jacobson (1999). This scheme is similar to the APD scheme, but the vapor pressure here is only a function of temperature. For ice particle growth by $\mathrm{H}_{2} \mathrm{O}$ vapor deposition, we use a deposition coefficient of 0.5 as a baseline value, motivated by laboratory studies (Haynes et al., 1992).

We emphasize that it is of great importance to accurately simulate the relative humidity in the chamber volume in any study of freezing nucleation. As discussed with the help of Fig. 1, the total $\mathrm{H}_{2} \mathrm{O}$ mixing ratio varies as a function of time due to interactions between the gas phase and the ice-coated walls. Independent measurements of the $\mathrm{H}_{2} \mathrm{O}$ concentration in the gas phase are not available. The question arises how to consider these wall effects in the model.

We constrain our simulations with the measured total water mixing ratios, but calculate the time-dependent partitioning of $\mathrm{H}_{2} \mathrm{O}$ between the gas phase, the aerosol phase, and the ice phase explicitly. At each time step, we increase the model gaseous $\mathrm{H}_{2} \mathrm{O}$ mixing ratios corresponding to the increase of the FISH data during the cooling phase,

\section{$\mathrm{H}_{2} \mathrm{O}$ (total) $)_{\mathrm{FISH}} \uparrow \longrightarrow \mathrm{H}_{2} \mathrm{O}(\text { gas })_{\text {APSC }} \uparrow$,}

and remove the model ice water corresponding to the decrease of the FISH data after freezing

\section{$\mathrm{H}_{2} \mathrm{O}$ (total) $)_{\mathrm{FISH}} \downarrow \longrightarrow \mathrm{H}_{2} \mathrm{O}$ (ice) APSC $_{\text {AP }}$.}

In this manner, both, $\mathrm{H}_{2} \mathrm{O}$ fluxes from the chamber walls (increasing $q$ ) and losses of ice water (decreasing $q$ ) are implicitly taken into account, reducing uncertainties in the simulated time history of relative humidity. Recall the reasons for the loss of ice water after the cooling phase: sedimentation of large crystals; particle losses caused by impaction on the chamber walls or on the mixing fan; undersampling of large crystals by the FISH instrument. At each time step, we decrease the modeled ice water content by subtracting the value $q(t)-q(t+\Delta t) \geq 0$, starting from the ice mass present in the largest bin of the ice crystal size distribution, until the modeled total water content becomes equal to the value indicated by the FISH instrument. Of course, this removal of ice mass in the model is not intended to be a realistic calculation of the above-mentioned ice water losses.

The degree to which remaining uncertainties caused by the precision and accuracy of the FISH and temperature measurements affect the simulation results are addressed in Sect. 6, along with other sensitivity studies. We note, however, that the decrease of $q$ after the cooling phase is not rele-

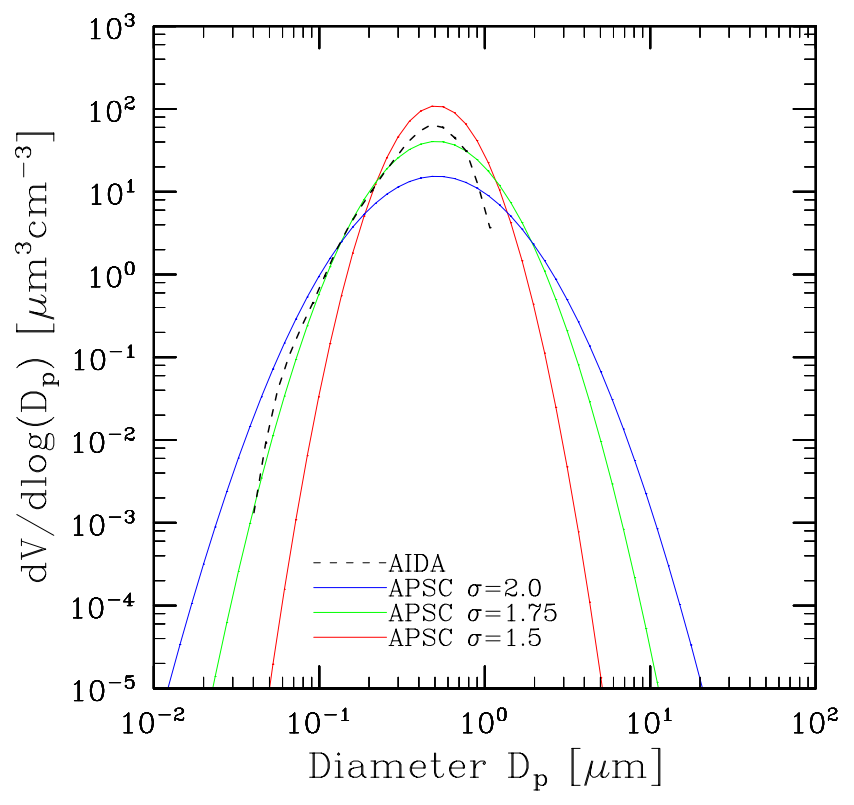

Fig. 3. Wet initial aerosol volume size distributions for the case study shown in Fig. 2. The solid curves represent model fits to the AIDA measurement represented by the dashed curve. The green curve is used in the baseline simulations.

vant for our study, as the freezing process is terminated while $q$ is still increasing.

\section{Case study at $202 \mathrm{~K}$}

We analyze in detail a cooling event starting at $202 \mathrm{~K}$ and an initial pressure of $180 \mathrm{hPa}$ (experiment A3_1 as noted in the companion paper); see Fig. 2. The total time of the simulation is $40 \mathrm{~min}$, starting $180 \mathrm{~s}$ before the chamber cooling.

\subsection{Initial aerosol size distribution}

The dashed curve in Fig. 3 represents the initial aerosol volume distribution measured in the AIDA chamber with the help of a differential mobility analyser (Möhler et al., 2003). In the APSC simulation, we fit this distribution with a dry mean mass radius of $0.16 \mu \mathrm{m}$ and a geometric standard deviation of $\sigma=1.75$ and let the resulting aerosol equilibrate with the available water vapor (green curve). We use these aerosol parameters as baseline values in the model.

Freezing predominantly occurs in the large size portion of the aerosol spectrum, since the homogeneous nucleation probability increases with the liquid aerosol volume (Pruppacher and Klett, 1997). Unfortunately, there is only very limited experimental information about particle sizes greater than $\sim 1 \mu \mathrm{m}$.

To investigate the influence of the initial aerosol size distribution on the number of nucleated ice particles, we have also run the model with a narrower size distribution $(\sigma=1.5$, red 
curve), and a distribution with larger liquid particles $(\sigma=2$, blue curve). The narrow size distribution is a good representation of measured total particle volume, whereas the broad distribution yields a better fit of the measured total number concentration of aerosol particles. The results of these sensitivity studies are presented in Sect. 6 .

\subsection{Relative humidity}

The simulated time evolution of RHI is shown in Fig. 4. Initially, gaseous $\mathrm{H}_{2} \mathrm{O}$ is in equilibrium with the ice-saturated chamber walls. However, our simulation starts with a RHI of only $90 \%$. This offset is caused by a combination of the experimental uncertainties in measuring $T$ and $\mathrm{H}_{2} \mathrm{O}$ and wall temperature inhomogeneities that are not fully captured by the 4 independent measurements of the wall temperature from which the mean wall temperature is calculated (Möhler et al., 2003). (The mean gas temperature also results from 4 measurements at different locations in the chamber. In contrast to the wall measurements, however, rapid mixing in the chamber ensures that inhomogeneities of $T$ in the AIDA volume remain relatively small.)

While the pressure drop in the chamber reduces the vapor pressure of $\mathrm{H}_{2} \mathrm{O}$, the ice saturation pressure drops more rapidly due to the decreasing gas temperature. Thus, cooling of the gas leads to a rapid increase of RHI. For the given conditions, the measurements by Koop et al. (2000) yield an approximate threshold value for homogeneous ice nucleation $\left(\mathrm{RHI}_{\text {nuc }}\right)$ of $\sim 160 \%$. (More precisely, $\mathrm{RHI}_{\text {nuc }}$ varies from $161 \%$ to $157 \%$ for freezing droplet radii in the range $0.1 \mu \mathrm{m}$ to $5 \mu \mathrm{m}$ and a freezing time scale of $\sim 1 \mathrm{~min}$.) When this threshold is exceeded at around $300 \mathrm{~s}$, a fraction of the aerosol particles start undergoing the phase transition. The black and red circles mark the freezing onset conditions obtained with the APSC and measured in the AIDA, respectively, as discussed in more detail in Sect. 4.3. How far the RHI can exceed the critical value depends on the number of ice crystals formed, which in turn depends on $T, d T / d t$, and aerosol freezing properties. We come back to this issue when discussing Fig. 11.

After the onset of freezing, rapid depositional growth of the nucleated ice crystals lowers the gas phase concentration of $\mathrm{H}_{2} \mathrm{O}$ and halts the rise of RHI due to ongoing cooling of the chamber air. (According to Fig. 2, $T$ continues to fall until $t=600 \mathrm{~s}$.) Despite the low temperature and the high cooling rate, which both favor larger differences between the peak and the threshold values of RHI, the peak RHI of $165.5 \%$ is only $3.5 \%$ larger than $\mathrm{RHI}_{\text {nuc }}$. When RHI starts falling below $\mathrm{RHI}_{\text {nuc }}$, no further ice particles are formed, but depositional growth of the existing ice particles continues. Exchange of $\mathrm{H}_{2} \mathrm{O}$ with the aerosol particles does not affect the evolution of RHI significantly, as the water content in the aerosol particles remains small; see Sect. 4.5 and Fig. 10.

After about $600 \mathrm{~s}$, when $T$ begins to rise due to the heat flux from the chamber walls (recall Fig. 2), RHI comes close

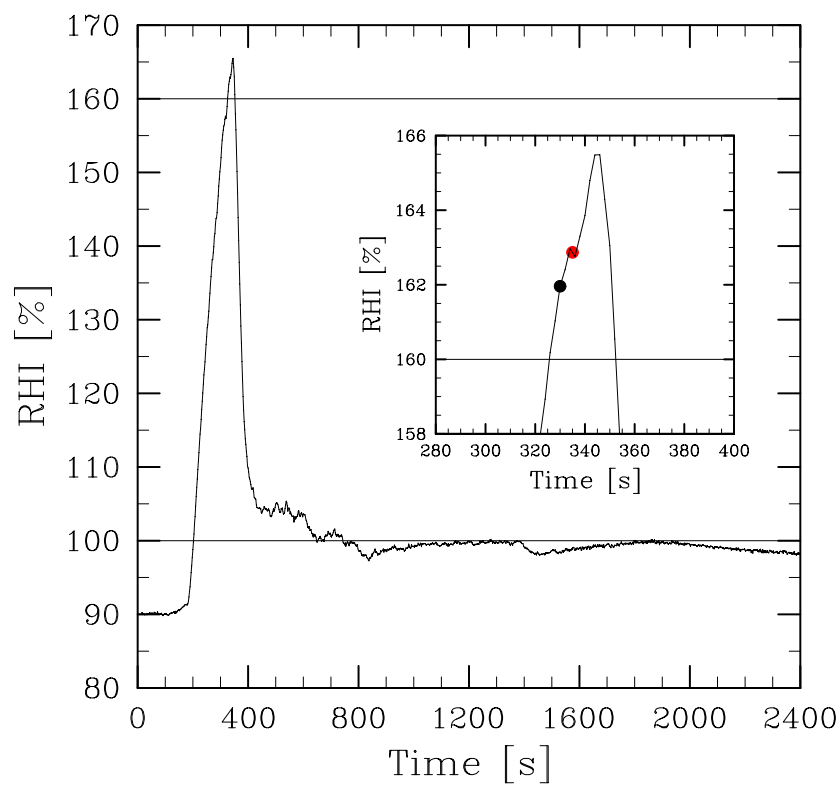

Fig. 4. Modeled relative humidity with respect to ice. The horizontal line at $160 \%$ indicates the critical supersaturation for homogeneous ice nucleation at $198 \mathrm{~K}$ for particles with a diameter of $\sim 0.4 \mu \mathrm{m}$ and a freezing time scale of $1 \mathrm{~min}$ (Koop et al., 2000); the corresponding freezing temperature is defined in Fig. 6. The RHI reaches a peak value of $165.5 \%$. The black (red) circle marks the freezing onset conditions derived from the model (depolarisation measurements), see Fig. 7.

to $100 \%$. At this time, $p$ is still falling, reducing the $\mathrm{H}_{2} \mathrm{O}$ number density. On the other hand, the FISH data indicate that $q$ rises due to a net molecular flux from the chamber walls. This $\mathrm{H}_{2} \mathrm{O}$ flux compensates the pressure-induced decrease of $\mathrm{H}_{2} \mathrm{O}$ and re-establishes equilibrium between the moisture in the chamber and the ice-coated chamber walls at the lower pressure, as will be elucidated in Sect. 4.5.

We also ran the model assuming a constant total $\mathrm{H}_{2} \mathrm{O}$ mixing ratio (not shown here), i.e. ignoring the observed increase in total water during cooling. These calculations show a continuous fall of RHI to values below $70 \%$ after $800 \mathrm{~s}$, in sharp contrast to the measurements. This underlines the importance to constrain such types of simulations with accurate measurements of $q$ and $T$, which are hard to obtain in airborne field campaigns.

On two occasions near $800 \mathrm{~s}$ and near $1400 \mathrm{~s}$, RHI drops slightly below ice saturation (Fig. 4). These drops in RHI are correlated with a smaller pumping speed and therefore with an enhanced temperature increase (recall Fig. 2). The brief undersaturations force the ice particles to partially evaporate, which tends to establish equilibrium again. The explanation of this subtle detail in the evolution of a highly sensitive quantity such as RHI increases the confidence in the ability of our model to simulate the physics of the freezing and growth processes correctly. 


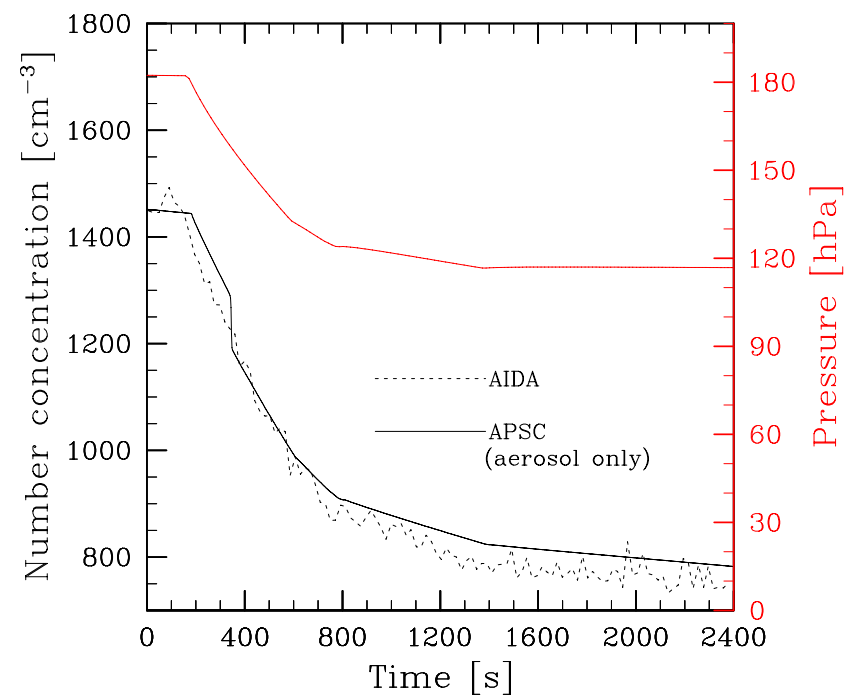

Fig. 5. Pressure and total number concentrations of particles in the chamber versus time. The dashed curve depicts the aerosol measurements (sum of concentrations of aerosol and ice particles in the diameter range $20 \mathrm{~nm}$ to $3 \mu \mathrm{m}$ ). In the simulation (solid curve, aerosol particles only), freezing of a small fraction of the aerosol particles is indicated by the sharp decrease at $345 \mathrm{~s}$. During the most of the time, the total particle number concentration closely follows the observed pressure drop (red curve).

\subsection{Particle number concentrations}

The simulation starts with a reservoir of $1460 \mathrm{~cm}^{-3} \mathrm{H}_{2} \mathrm{SO}_{4}$ aerosol particles, which is close to the observed total number concentration in the AIDA chamber. The volume expansion via pumping causes the aerosol number concentration to decrease; see Fig. 5. Over most of the simulation period, the observed and simulated particle concentrations agree well and closely follow the pressure evolution. At constant pressure conditions before $200 \mathrm{~s}$ and after about $1400 \mathrm{~s}$ the total number concentration also slightly decreases. This is caused by the loss processes of $\mathrm{H}_{2} \mathrm{SO}_{4} / \mathrm{H}_{2} \mathrm{O}$ aerosols in the AIDA chamber (recall Sect. 3).

An exceptional change occurs at $345 \mathrm{sec}$. At this point, the modeled aerosol number concentration exhibits a sharp decrease, indicating the transition of the liquid to the ice phase. Freezing occurs within only several tens of seconds, because the occurrence of this sharp decrease coincides with the peak of the RHI-curve as shown in Fig. 4. (We have used the fact that most of the ice crystals form in the peak region of the RHI curve in the analytical parameterization of cirrus formation (Kärcher and Lohmann, 2002).) The simulated aerosol concentration drops by about 90 particles per $\mathrm{cm}^{3}$, which is equal to the number of ice particles formed; see Fig. 6. In the experimental data shown in Fig. 5, the drop of the particle concentration cannot be discerned, because the particle counter measures the sum of aerosol and ice particle concentrations (although at later times larger ice particles may not

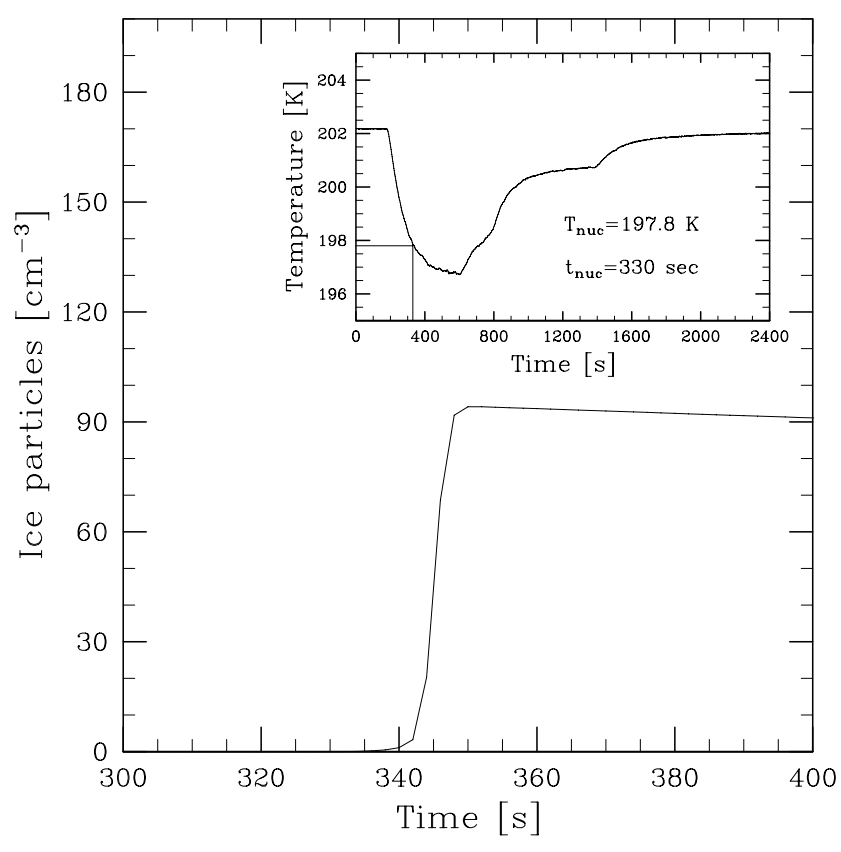

Fig. 6. Modeled number density of ice particles versus time. Per definition, the onset of freezing is found at $330 \mathrm{sec}$, the time when the concentration of ice particles exceeds $10^{-3} \mathrm{~cm}^{-3}$ (not visible). The corresponding freezing temperature is $T_{\text {nuc }}=197.8 \mathrm{~K}$.

have been detected due to the high-size cut-off of the particle counter and depending on the evaporation rate of the particles in the detection system).

In Fig. 6, we define the onset of freezing at 330 s. A maximum ice number density of $94 \mathrm{~cm}^{-3}$ is reached within $20 \mathrm{~s}$. Further nucleation of ice particles is prevented by the fall of RHI below the freezing threshold. The time scale $\tau$ of the nucleation event at the freezing temperature of $198 \mathrm{~K}$ is inversely proportional to the cooling rate $d T / d t$, as given by Kärcher and Lohmann (2002):

$\tau[\mathrm{s}]=\left(78.5 \frac{d T}{d t}\left[\mathrm{~K} \mathrm{~s}^{-1}\right]\right)^{-1}$.

Inserting the observed cooling rate $d T / d t=0.012 \mathrm{~K} \mathrm{~s}^{-1}$ at $198 \mathrm{~K}$, we obtain $\tau \sim 1 \mathrm{~s}$. We have checked that this compares well with the full width at half maximum of the sizeintegrated nucleation pulse $J(t)$, which is $\sim 3 \mathrm{~s}$ according to our simulation.

In Fig. 7, the simulated total ice number density is compared with the AIDA data (black curve) representing all ice particles with diameters exceeding $1.5 \mu \mathrm{m}$ (Möhler et al., 2003). Only particles $>1.5 \mu \mathrm{m}$ are counted as ice particles in the optical particle counter measurements in order to avoid counting of large aerosol particles. In the model, the difference between the total ice particle concentrations and the concentrations of ice particles $>1.5 \mu \mathrm{m}$ (not shown) is very small. We will return to this issue in Sect. 6.3. 


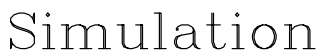

\section{Observation}
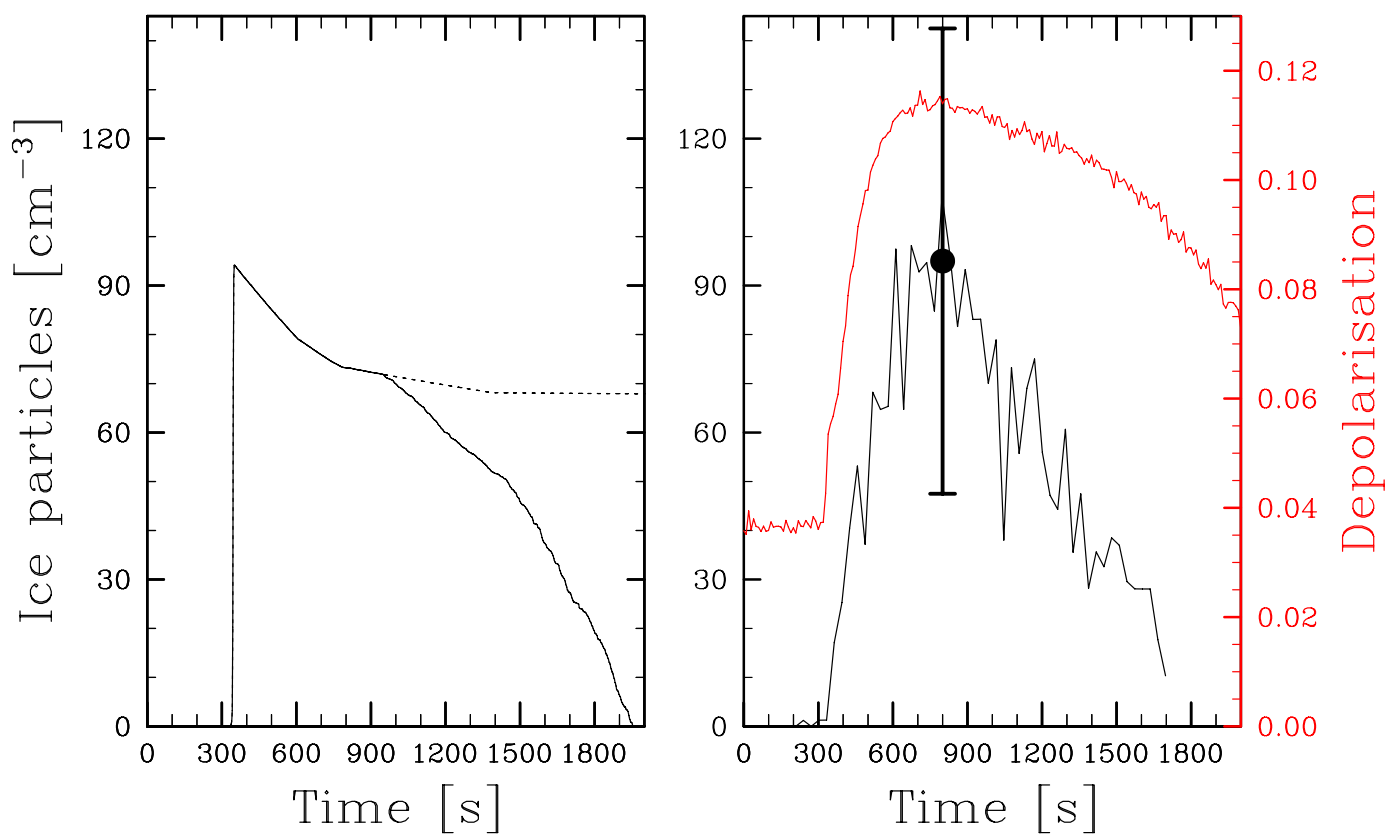

Fig. 7. Ice particle number densities versus time (modeled total number concentrations on the left panel, measured concentrations for particles with diameters $>1.5 \mu \mathrm{m}$ on the right panel). The simulation shows two results with and without loss of ice water caused by sedimentation, wall impaction, or undersampling of large ice particles (solid and dashed curve, respectively). The simulated evolution of concentrations of ice particles with diameters $>1.5 \mu \mathrm{m}$ (not shown) is almost identical to the curves shown. The vertical bar depicts the experimental uncertainty in measuring ice number densities with the optical particle counter. The red curve depicts the measured depolarisation signal detected with an Argon laser, ascribed to the formation and growth of ice particles. The freezing onset conditions from the APSC and the AIDA depolarisation signal are also shown as black and red circles in Fig. 4.

If we take into account the above-mentioned losses of ice water by empirically relating the simulated ice water content to the observed decrease of the total water mixing ratio (Sect. 3), the simulation shows a similar decrease of the ice particle number density as the measurements, compare the solid and dotted curves in Fig. 7 taken from the simulation.

Both, the onset of freezing and the total number density are very well captured by the simulation. The sharp rise in depolarisation of backscattered laser light (red curve) coincides nicely with the detection of particles by the optical particle counter, which is only sensitive to large (ice) particles.

The delayed increase of the ice particle concentration measured with the optical particle counter relative to the APSC result is not linked to the $1.5 \mu \mathrm{m}$ counting limit. It is rather caused by the partial evaporation of ice particles in the measuring device (Möhler et al., 2003). In the early stages of ice particle growth, the smallest particles detected by the instrument experience a heating and evaporate and shrink to diameters below $1.5 \mu \mathrm{m}$, where they cannot be distinguished from large aerosol particles. As the ice particles in the chamber grow, this effect becomes less and less important and it is unlikely that the measurements underestimate the peak number density of ice crystals.

\subsection{Aerosol size distributions and chemical composition}

Figure 8 displays the changes in modeled size distributions at the time of particle freezing. We first discuss the ice particle spectrum in the bottom panel, given as the number density of ice particles in each bin. The first ice particles are seen at $\sim 330 \mathrm{~s}$ with a mean number diameter near $0.8 \mu \mathrm{m}$. Up to $350 \mathrm{~s}$, the mean size increases only slightly, but the concentration rises by a factor $10^{4}$, indicating slow growth and rapid freezing. Thereafter, freezing is terminated and the ice particles grow to a mean diameter of $2.4 \mu \mathrm{m}$ at $380 \mathrm{~s}$, a size range where growth is almost fully controlled by diffusion. As the radial growth rate in the diffusion regime is inversely proportional to the particle size, small particles grow faster than larger ones, creating a relatively narrow size spectrum of pristine ice particles. The separation into rapid freezing and subsequent relatively slower growth supports the interpretation of the measured depolarisation of the backscattered laser light at the time of nucleation, as detailed in Sect. 3.1 of the companion paper (Möhler et al., 2003).

As the aerosol size distribution in Fig. 8 (top panel) shows, no freezing of liquid sulfuric acid aerosol particles occurs for diameters larger than $\sim 4 \mu \mathrm{m}$. At first glance, this seems surprising because the homogeneous freezing rate should in- 


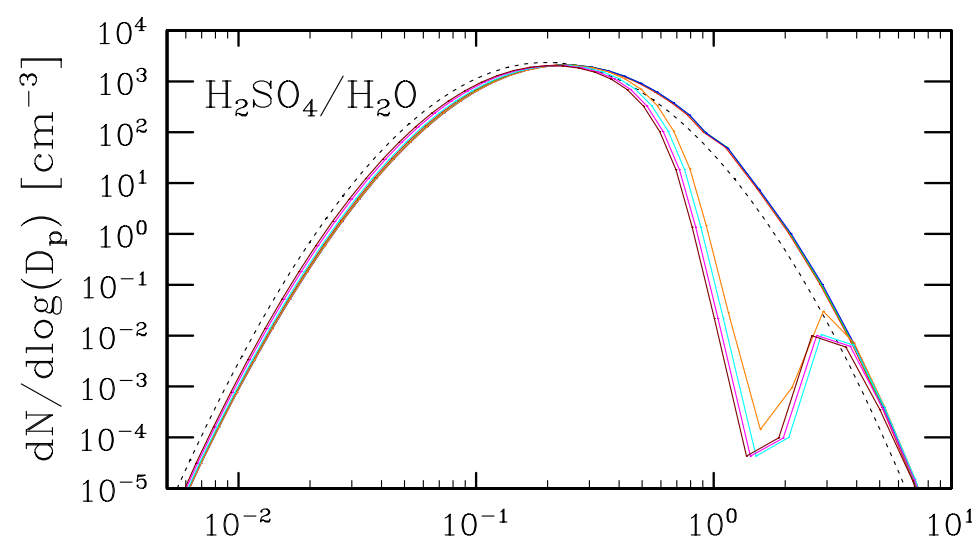

Time $[\mathrm{s}]$
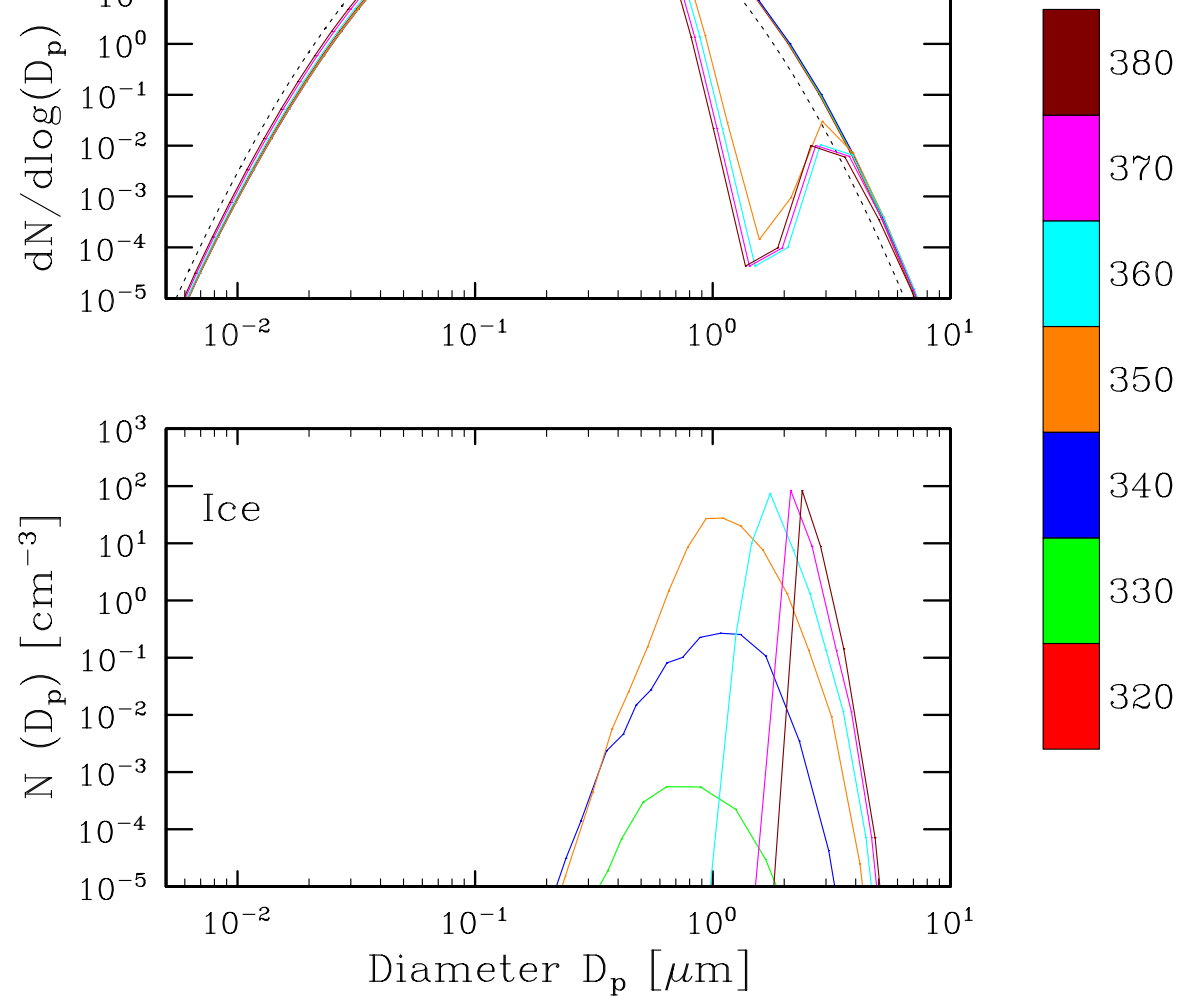

Fig. 8. Modeled aerosol number size distributions (top panel) and ice particles number size distributions (bottom panel) around the time of ice nucleation. The color coding displays the simulation time advancing in steps of $10 \mathrm{~s}$. The dotted curve in the top panel is the initial aerosol size distribution.

crease with the particle volume. These largest aerosol particles remain liquid because transport of water vapor to them is limited by diffusion in the gas phase. During the rapid cooling in this experiment, the water activity in the larger particles lags behind the relative humidity. Hence, at the time when freezing of e.g. $1 \mu \mathrm{m}$ particles commences, the water content (or water activity) of larger (e.g. $4 \mu \mathrm{m}$ ) particles is too small and the solution droplets are too acidic to undergo freezing.

This finding is further supported by Fig. 9, showing $\mathrm{H}_{2} \mathrm{O}$ mass fractions $W$ as a function of time and particle size. The dotted curve displays the mass fraction distribution at the beginning of the simulation. As long as no freezing occurs, condensational growth driven by the increase of relative humidity dilutes the supercooled droplets. At $340 \mathrm{~s}, W$ peaks at $75 \%$ in $1 \mu \mathrm{m}$-sized droplets. Note that very large droplets with diameters above $20 \mu \mathrm{m}$ stay at relatively low $\mathrm{H}_{2} \mathrm{O}$ mass fractions close to their initial value.

Aerosol particles below $0.1 \mu \mathrm{m}$ in diameter take up little $\mathrm{H}_{2} \mathrm{O}$, too, due to the Kelvin growth barrier. In contrast to the large droplets, the small droplets always stay very close to equilibrium with $\mathrm{H}_{2} \mathrm{O}$ in the gas phase, and react almost instantaneously to the changes of RHI. Because of the diffusion limitation, the larger aerosol particles evaporate water molecules more slowly when RHI starts to fall after 340 min, as indicated by the humps in the curves shown in Fig. 9 in the diameter range $5-10 \mu \mathrm{m}$.

\subsection{Partitioning of water}

As detailed in Sect. 3, all simulations are constrained with measured total water mixing ratios, so that at each time, total water in the model equals its measurement value. Figure 10 shows the modeled partitioning of $q$ into water vapor, liquid (aerosol) water content, and ice water content, which cannot be inferred from the measurements.

Initially, the major part of total water resides in the gas phase, with only little liquid water present in the aerosol. The aerosol water content increases owing to condensational growth of the supercooled droplets before freezing, thereafter it decreases. The zoom of aerosol water content inside Fig. 10 shows a steep decrease between $340 \mathrm{~s}$ and $350 \mathrm{~s}$. 
Time $[\mathrm{s}]$

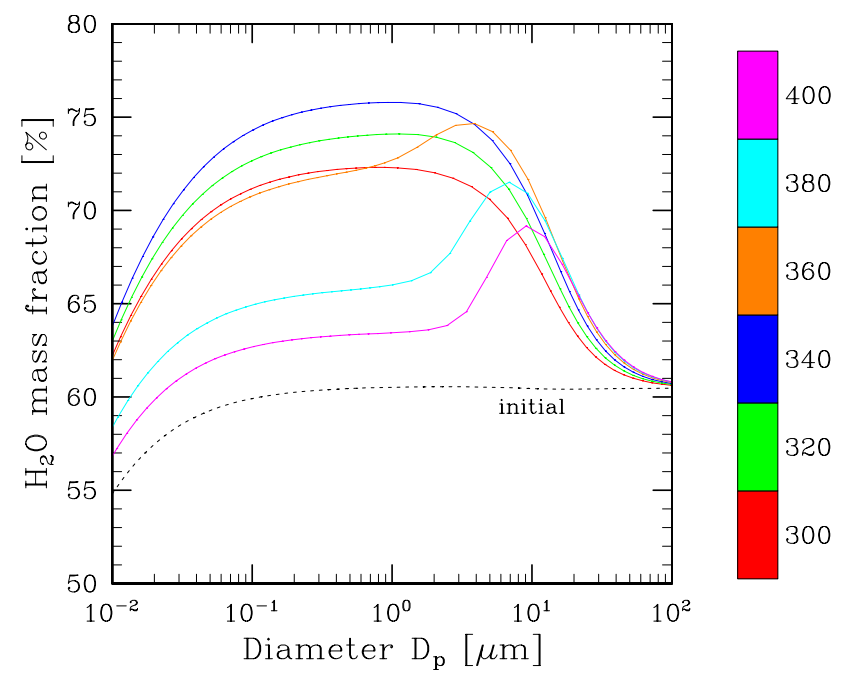

Fig. 9. Modeled size-resolved $\mathrm{H}_{2} \mathrm{O}$ mass fractions of the $\mathrm{H}_{2} \mathrm{SO}_{4} / \mathrm{H}_{2} \mathrm{O}$ droplets around the time of ice nucleation. The dotted line shows the initial aerosol water content before cooling.

This part of aerosol $\mathrm{H}_{2} \mathrm{O}$ is lost by the conversion of a fraction of the aerosol into ice particles (compare with Fig. 6). In contrast, the subsequent slower decrease is caused by the evaporation of $\mathrm{H}_{2} \mathrm{O}$ molecules from the aerosol with falling $\mathrm{RHI}$; this is the well known fact that ice particles grow at the expense of supercooled droplets if they coexist.

The gaseous $\mathrm{H}_{2} \mathrm{O}$ reservoir is depleted by deposition onto ice particles after freezing between $300 \mathrm{~s}$ and $400 \mathrm{~s}$. This loss of gaseous water on ice is partly compensated by the wall flux of $\mathrm{H}_{2} \mathrm{O}$ molecules into the gas, as the increasing total water mixing ratio reveals.

At around $800 \mathrm{~s}$, a maximum ice water content of almost 11 ppmv is reached. On the other hand, we find a decrease of only $\sim 5 \mathrm{ppmv}$ in the gas phase due to deposition on the ice particles. This implies that most of $\mathrm{H}_{2} \mathrm{O}$ molecules released from the chamber walls deposit very quickly onto the growing crystals. In fact, the time scale for depletion of the $\mathrm{H}_{2} \mathrm{O}$ number density is given by $1 /(4 \pi \operatorname{Dr} \beta(r) n) \simeq 25 \mathrm{~s}$, evaluated with the diffusion coefficient $D=0.211 \mathrm{~cm}^{2} \mathrm{~s}^{-1}$ $(1013.25 \mathrm{hPa} / \mathrm{p})(T / 273.15 \mathrm{~K})^{1.94} \simeq 0.9 \mathrm{~cm}^{2} \mathrm{~s}^{-1}$, an ice particle radius $r=1 \mu \mathrm{m}$, the factor $\beta=0.4$ controlling the transition between kinetic and diffusive growth regime, and the peak ice particle number density $n=94 \mathrm{~cm}^{-3}$. The transitional factor is given by $1 / \beta=1+4 \lambda /(3 \alpha r)$, where $\lambda=0.53 \mu \mathrm{m}$ is the effective mean free path for diffusion of $\mathrm{H}_{2} \mathrm{O}$ molecules in air (at $200 \mathrm{~K}$ and $180 \mathrm{hPa}$ ). As noted before, the deposition coefficient $\alpha$ is equal to 0.5 in the baseline simulations.

At $800 \mathrm{~s}$ and $1400 \mathrm{~s}$, the RHI drops slightly below $100 \%$ (recall Fig. 4). This leads to a transient evaporation of the ice particles. In concert with the wall flux, this evaporation leads to an increase of gaseous $\mathrm{H}_{2} \mathrm{O}$ (Fig. 10) until the cool- ing phase is finished.

The dotted curves display the expected behavior of the system in the absence of losses of ice water. The losses (for which potential reasons have been mentioned in Sect. 3) become important after $900 \mathrm{~s}$. While such effects cause the ice water content to decrease much faster than by evaporation alone, its impact on the gas phase concentration is very limited as can be seen in Fig. 10. In summary, it is important to note that the partitioning of water shown in Fig. 10 is primarily driven by the $\mathrm{H}_{2} \mathrm{O}$ wall flux and the interaction with ice, both controlling the time history of the relative humidity.

\section{Experiments in other temperature regions}

We present APSC results with supercooled $\mathrm{H}_{2} \mathrm{SO}_{4} / \mathrm{H}_{2} \mathrm{O}$ droplets covering initial temperatures from $194 \mathrm{~K}$ to $235 \mathrm{~K}$ and cooling rates at the point of freezing in the range $0.5 \mathrm{~K} \mathrm{~min}^{-1}$ to $2.6 \mathrm{~K} \mathrm{~min}^{-1}$. To obtain parameters for lognormal aerosol size spectra at $t=0$, we have used the measured total $\mathrm{H}_{2} \mathrm{SO}_{4}$ masses and spectral width and varied the mean mass radii such that model and observed total aerosol number concentrations agreed, except for B4_1 and C1_1 (the experiment numbers as noted in Table 1 ), where $\sigma=1.8$ has been prescribed. In comparing APSC results with the AIDA data, we focus on total ice particle number densities, peak values of ice supersaturation and freezing threshold values $\left(\mathrm{RHI}_{\text {nuc }}\right)$, the times of the onset of freezing, and the $\mathrm{H}_{2} \mathrm{SO}_{4}$ mass fractions $\left(\mathrm{W}_{\text {nuc }}\right)$ in the freezing particles. These values correspond the model output (besides other details of the $\mathrm{H}_{2} \mathrm{O}$ partitioning) left unconstrained by experimental data and provide a stringent test of our ability to accurately simulate homogeneous ice formation.

\subsection{Supersaturations}

Figure 11 compares the modeled values of peak RHI (filled circles) and $\mathrm{RHI}_{\text {nuc }}$ (open circles) with the observed threshold values for homogeneous ice nucleation in the AIDA chamber (open squares). Shown as a dashed (dotted) curve is the threshold RHI as a function of $T$ for which a particle with radius $0.25 \mu \mathrm{m}(1 \mu \mathrm{m})$ freezes in one second (one minute), derived using the nucleation rate parameterization provided by Koop et al. (2000). Both curves approximately bracket the range of particle sizes and nucleation time scales in the AIDA. In the first case (dashed curve), the critical nucleation rate $J$ and the difference $\Delta a=a-a_{i}$ between the critical water activity and the activity at ice equilibrium take the value $J=1.5 \times 10^{13} \mathrm{~cm}^{-3} \mathrm{~s}^{-1}$ and $\Delta a=0.3204$; in the second case (dotted curve), we find $J=4 \times 10^{9} \mathrm{~cm}^{-3} \mathrm{~s}^{-1}$ and $\Delta a=0.305$.

Comparing the peak values with the freezing thresholds from the model, we observe that the difference between both is of the order of a few percent and tends to increase with decreasing temperature (cases A1_1, A3_1, A5_1). When $T$ 
Total

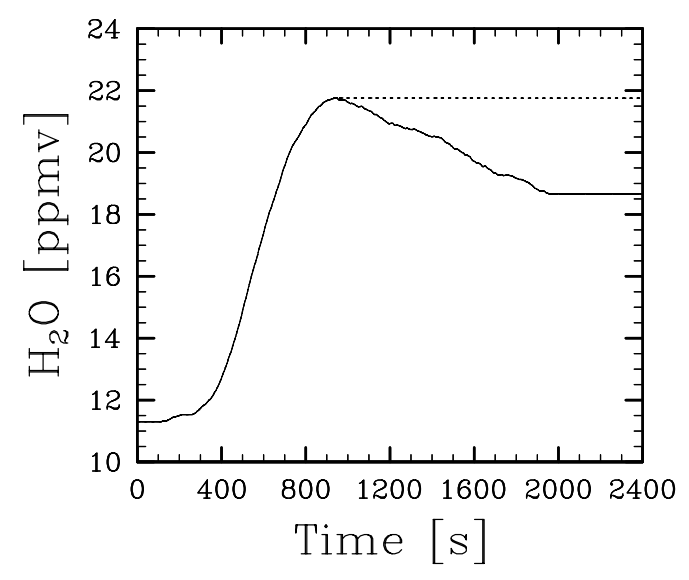

Aerosol

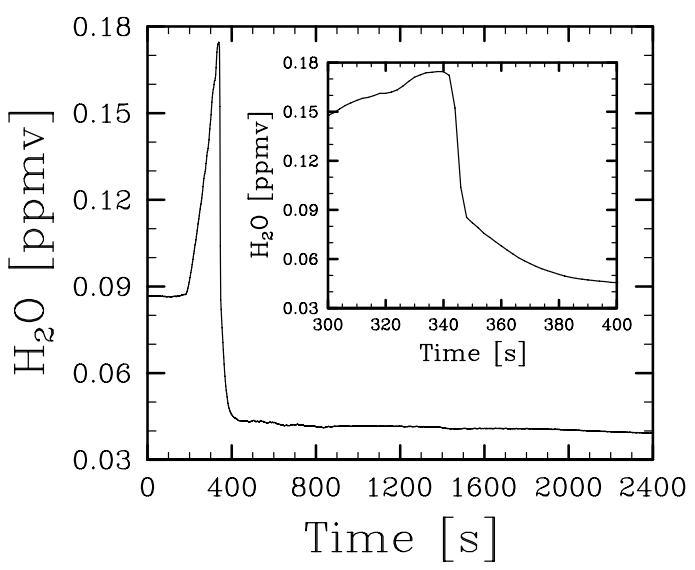

Gas Phase

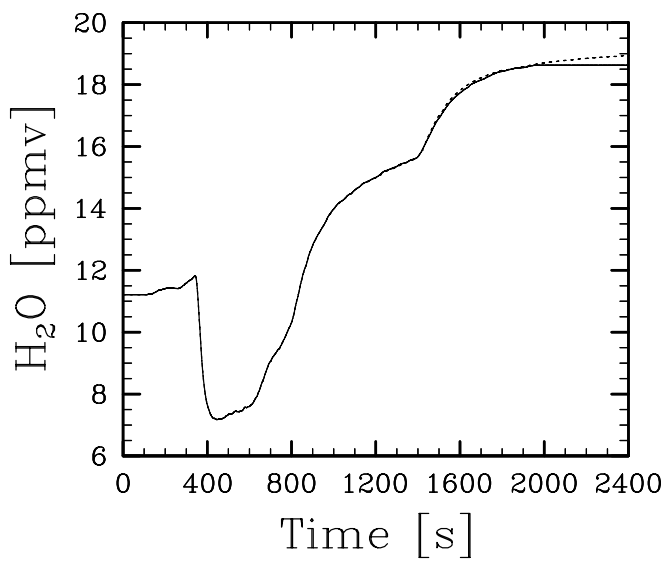

Ice

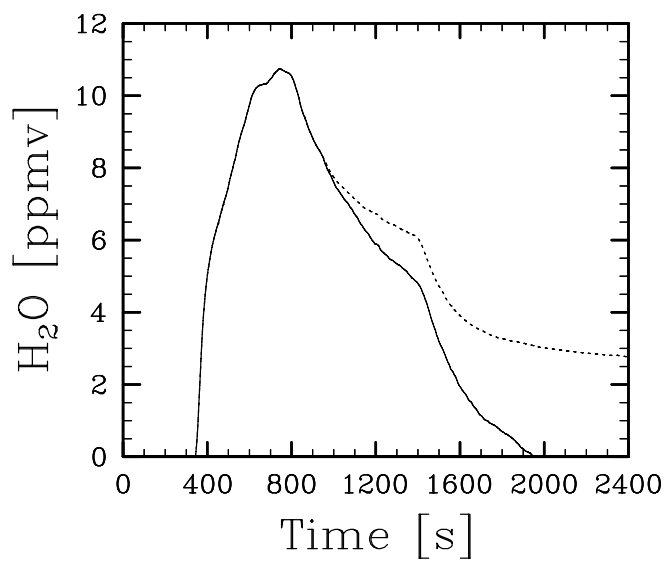

Fig. 10. Modeled partitioning of $\mathrm{H}_{2} \mathrm{O}$. The total mixing ratio is constrained by the FISH measurements, while the gas phase, aerosol phase, and ice phase water mixing ratios are computed by the APSC model with (solid curves) or without (dotted curves) the effects of ice water losses after $900 \mathrm{~s}$.

falls, ice particle growth rates become slow, allowing RHI to take larger peak values driven by the relatively strong cooling rates prevailing during these experiments. The difference is larger for the highest temperature considered (case C1_1) because the cooling rate was much higher (by a factor $3-4$ ) in this experiment, which compensates the pure temperature effect. These kinetic effects explain why the peak RHI values lie above the dashed and dotted curves that represent onset RHI values given by Koop et al. (2000) that have been derived assuming equilibrium between aerosol particles and water vapor and a freezing time scale of $1 \mathrm{~min}$.

With falling $T$, we also observe an increasing tendency for the onset values to lie above the dashed and dotted curves. This is caused by the non-equilibrium aerosol compositions affecting the large aerosol particles (diameter $>2 \mu \mathrm{m}$ ) as discussed in Sect. 4.4. Recall from Fig. 6 that in the model, the onset of ice formation was defined at the time when the number of ice particles exceeded $10^{-3} \mathrm{~cm}^{-3}$. (A similarly low threshold concentration likely determines the experimental onset of ice formation.) The largest particles with such low concentrations would freeze first if they were in equilibrium with the ambient water vapor, but they stay liquid because of their non-equilibrium composition. In contrast, smaller particles in the diameter range $0.1-1 \mu \mathrm{m}$ stay close to equilibrium and freeze first (see Figs. 8 and 9). The lower the temperature, the smaller are the first freezing particles and the higher are their freezing relative humidities because the nucleation rate per unit time is proportional to the particle volume. This causes the actual $\mathrm{RHI}_{\text {nuc }}$ values to be higher than the corresponding (equilibrium) values evaluated with a constant (e.g., 0.5 or $2 \mu \mathrm{m}$ ) particle diameter and delays the onset of freezing

In the atmosphere, kinetic and non-equilibrium effects may occur in cirrus clouds at cooling rates similar to those 
measured in the AIDA chamber; this has also been found previously on the basis of field measurements (Heymsfield and Miloshevich, 1995).

The calculated onset RHIs are quite insensitive to changes of temperature or the total $\mathrm{H}_{2} \mathrm{O}$ mixing ratios. Within the variations of $T$ and $\mathrm{H}_{2} \mathrm{O}$ shown in Figs. 12 and 13 (top panels), the onset RHI vary only by $0.3 \%$. The freezing onset times are more sensitive to changes of $T$ and $\mathrm{H}_{2} \mathrm{O}$ mixing ratio, as discussed in Sect. 5.2.

Apart from two cases $\mathrm{A} 5 \_1$ and $\mathrm{C} 1 \_1$, the modeled and measured $\mathrm{RHI}_{\text {nuc }}$ values do not differ by more than $3 \%$, which is well within the absolute experimental uncertainty of RHI of $\pm 8-12 \%$ (the uncertainty increases with decreasing temperature). In case A5_1, the difference between modeled and measured $\mathrm{RHI}_{\text {nuc }}$ may be explained by an additional systematic error caused by heterogeneous freezing artifacts of background particles which cannot totally be ruled for the very first experiments of series A (Möhler et al., 2003).

The discrepancy seen in the case $\mathrm{C}_{-}{ }_{1}$ is more difficult to explain. It may be caused by temperature fluctuations of small, turbulent air parcels (eddies) following an adiabatic temperature evolution for short periods of time. Therefore, the formation of ice may have occurred in such eddies at somewhat lower temperatures than the mean gas temperature measured with time resolution of about $3-5 \mathrm{~s}$ (Möhler et al., 2003). The onset RHI derived with a lower temperature would lead to a higher value, in better agreement with the model result. As a second explanation, the difference could be caused by the larger cooling rate. When the cooling rate is large, $\mathrm{RHI}_{\text {nuc }}$ becomes sensitive to even small shifts in the freezing onset time.

The threshold $\mathrm{RHI}_{\text {nuc }}$ from the model lies very close to the (solid) water saturation line in experiment C1_1. The supercooled droplets become water activated due to the very rapid cooling at the warm temperature and undergo freezing as nearly pure water droplets. It seems that water activation did not occur during this experiment. Under the conditions of case $\mathrm{C} 1 \_1$ (large cooling rate and warm temperature), the solution droplets take up great amounts of water and are strongly diluted. This is reflected by the relatively low acid mass fractions of $4.3 \%$. (The APSC yields a value of $16.1 \%$ when read off at the time $72 \mathrm{~s}$ when the AIDA reports the freezing onset.) Hence, it is interesting to study slight changes of the $\mathrm{H}_{2} \mathrm{O}$ vapor pressure parameterization for the nearly pure water droplets, the accuracy of which may be of the order of a few percent or so. If we lower the saturation vapor pressure of water by only $2.5 \%$ when the relative humidity exceeds $95 \%$ in a sensitivity study, the modeled $\mathrm{RHI}_{\text {nuc }}$ for case $\mathrm{C} 1 \_1$ is $3.6 \%$ lower and also the peak RHI lies just below the water saturation line (see also the model results listed in brackets in Table 1).

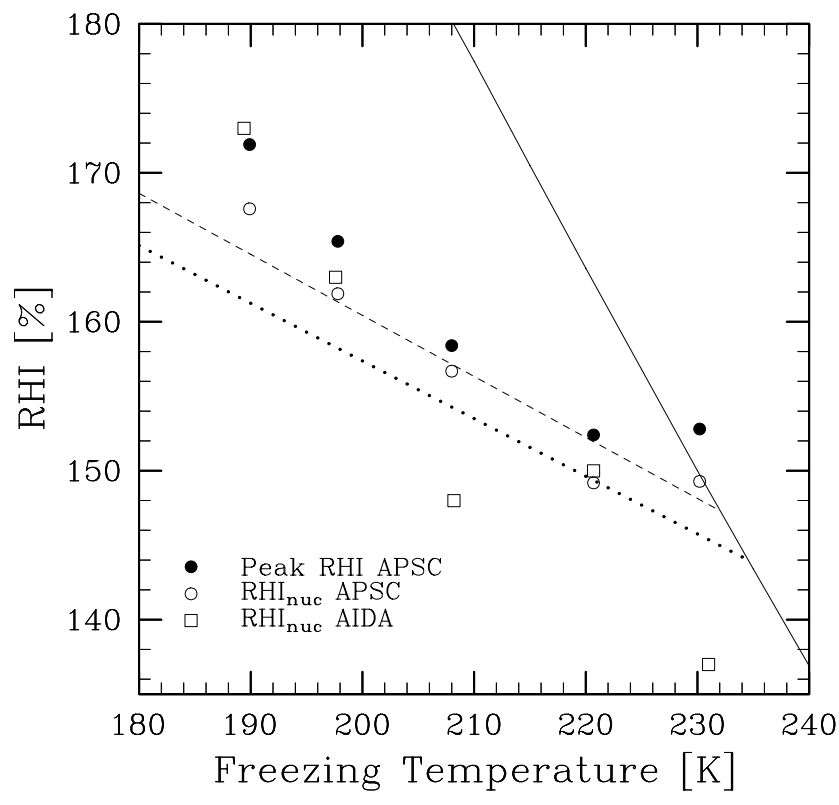

Fig. 11. Modeled baseline values of peak RHI and $\mathrm{RHI}_{\text {nuc }}$ (closed and open circles) and measured threshold values for homogeneous ice nucleation inside the AIDA chamber (squares). The solid line indicates RHI when liquid water is saturated. The dashed (dotted) line depicts $\mathrm{RHI}_{\text {nuc }}$ for which a particle with diameter 0.5 (2) $\mu \mathrm{m}$ freezes homogeneously in $\Delta t=1 \mathrm{~s}(1 \mathrm{~min})$, bracketing the freezing conditions in the AIDA chamber; we have computed these curves by using the nucleation rate $J$ from Koop et al. (2000) and solving $J(a, T) V \Delta t=1$ for the critical water activity $a$, or $\mathrm{RHI}_{\text {nuc }}$. Note that the freezing time scale $(\sim 1 \mathrm{~min})$ for the laboratory experiments of Koop et al. (2000) lies within the above range. The absolute experimental uncertainty of $\mathrm{RHI}_{\text {nuc }}$ increases from $\pm 8 \%$ at $230 \mathrm{~K}$ to $\pm 12 \%$ at $190 \mathrm{~K}$ (Möhler et al., 2003).

\subsection{Onset of freezing}

In the experiments, the onset time of freezing $t_{\text {nuc }}$ is determined by a sharp increase of the depolarisation of backscattered light from an Argon laser beam (Möhler et al., 2003). In the simulations, the freezing onset is defined as the time when the calculated ice number density exceeds $10^{-3} \mathrm{~cm}^{-3}$. Therefore, it is not straightforward to compare the modeled and measured freezing onset times. Nevertheless, as can be seen in Table 1, the model results represent the experimental data very well. The same holds for the freezing temperatures $T_{\text {nuc }}$ (also listed in Table 1), which can also be inferred from Fig. 11.

The coldest case A1_1 starting at $194.4 \mathrm{~K}$ seems to be an exception. Here, $t_{\text {nuc }}$ determined in the AIDA is much larger than the modeled value, causing the discrepancy in terms of the cooling rate listed in Table 1. One explanation could be the uncertainty in measuring the total water mixing ratio, which can influence the model results (see Sect. 6.1). If we lower the FISH value by 7.5\% (model results listed in brackets in Table 1), which is close to the experimental range of 
Table 1. Simulated freezing experiments with initial temperature $T_{0}$ and cooling rate $(d T / d t)_{\text {nuc }}=\gamma$. The cooling rates are determined at the times of the freezing onset. Assuming adiabatic cooling, these values would correspond to vertical velocities of the order $120 \mathrm{~cm} \mathrm{~s}^{-1}$, typical for convective updrafts or strong mesoscale (lee) waves. The AIDA experiment numbers shown in the first column are taken from Möhler et al. (2003). Further, modeled and measured onset times of freezing $t_{\text {nuc }}$, freezing temperatures $T_{\text {nuc }}$, and $\mathrm{H}_{2} \mathrm{SO}_{4}$ mass fractions $W_{\text {nuc }}$ at $t_{\text {nuc }}$ are listed. The onset times noted here refer to the beginning of chamber pumping to compare with Table 2 from Möhler et al. (2003). The non-equilibrium acid mass fractions are calculated for particles with a diameter of $1 \mu \mathrm{m}$, the observed values are derived from filter measurements assuming water equilibrium. The last two columns compare modeled and measured peak values of total ice particle number density $n$, including the experimental uncertainty of $\pm 50 \%$. The APSC results for case A1_1 listed in brackets represent a model run with a total $\mathrm{H}_{2} \mathrm{O}$ mixing ratio lowered by a value of 7.5\% (discussed in Sect. 5.2). The results listed in brackets for case $\mathrm{C} 1 \_1$ show the effect of lowering the saturation vapor pressure of $\mathrm{H}_{2} \mathrm{O}$ above $95 \%$ relative humidity by $2.5 \%$ (discussed in Sect. 5.1)

\begin{tabular}{cccccccccccc}
\hline \multirow{2}{*}{ AIDA } & \multirow{2}{*}{$T_{0}[\mathrm{~K}]$} & APSC & AIDA & \multicolumn{3}{c}{ APSC } & & AIDA & \multicolumn{2}{c}{ APSC } & AIDA \\
\cline { 3 - 11 } & & $\begin{array}{c}\gamma \\
{\left[\mathrm{K} \mathrm{min}^{-1}\right]}\end{array}$ & $\begin{array}{c}\gamma \\
{\left[\mathrm{K} \mathrm{min}^{-1}\right]}\end{array}$ & $\begin{array}{c}t_{\text {nuc }} \\
{[\mathrm{s}]}\end{array}$ & $\begin{array}{c}W_{\text {nuc }} \\
{[\%]}\end{array}$ & $\begin{array}{c}T_{\text {nuc }} \\
{[\mathrm{K}]}\end{array}$ & $\begin{array}{c}t_{\text {nuc }} \\
{[\mathrm{s}]}\end{array}$ & $\begin{array}{c}W_{\text {nuc }} \\
{[\%]}\end{array}$ & $\begin{array}{c}T_{\text {nuc }} \\
{[\mathrm{K}]}\end{array}$ & $\begin{array}{c}n \\
{\left[\mathrm{~cm}^{-3}\right]}\end{array}$ & $\begin{array}{c}n \\
{\left[\mathrm{~cm}^{-3}\right]}\end{array}$ \\
\hline A1_1 & 194.4 & -0.72 & 0.09 & 190 & 27.0 & 189.9 & 270 & 22.2 & 189.4 & 90 & no data \\
& & $(-0.06)$ & & $(268)$ & $(27.1)$ & $(189.4)$ & & & & $(41)$ & \\
A3_1 & 202.2 & -0.78 & -0.57 & 150 & 24.8 & 197.8 & 160 & 22.6 & 197.6 & 94 & $108 \pm 54$ \\
A5_1 & 212.6 & -0.9 & -0.88 & 152 & 21.2 & 208.0 & 127 & 23.3 & 208.2 & 34 & $42 \pm 21$ \\
B4_1 & 225.9 & -0.48 & -0.43 & 268 & 13.4 & 220.7 & 261 & 15.2 & 220.7 & 20 & $8 \pm 4$ \\
C1_1 & 235.3 & -2.58 & -2.75 & 96 & 4.3 & 230.2 & 72 & 16.2 & 231.0 & 346 & $>40$ \\
& & $(-2.58)$ & & $(91)$ & $(3.9)$ & $(230.4)$ & & & & $(245)$ & \\
\hline
\end{tabular}

uncertainty, the modeled and measured freezing onset times for case A1_1 agree very well again.

\subsection{Ice particle fractions}

Table 1 also compares modeled and measured peak values of the number density $n$ of ice particles. Except in the case A1_1, where no data are available, the agreement is excellent, demonstrating that the nucleation rate parameterization provided by Koop et al. (2000) can be safely employed to simulate homogeneous ice nucleation. In experiments A1_1, A3_1, and A5_1, the cooling rates increase slightly while the temperature increases by about $18 \mathrm{~K}$, explaining the decrease of $n$ in accord with theory (Kärcher and Lohmann, 2002).

\section{Sensitivity analysis}

Measured total water mixing ratio, temperature, and initial aerosol size distribution are subject to experimental uncertainties. We focus our sensitivity study on the influence of a variation of these measurement quantities on the modeled total ice particle number density. We also show the sensitivity of our simulations to changes of the deposition coefficient.

\subsection{Total water mixing ratio}

The total $\mathrm{H}_{2} \mathrm{O}$ mixing ratio displayed in Fig. 2 has an accuracy of $\pm 6 \%$. To conservatively evaluate how strong this experimental uncertainty can influence the baseline model run discussed in Sect. 4, we have performed a series of simu-
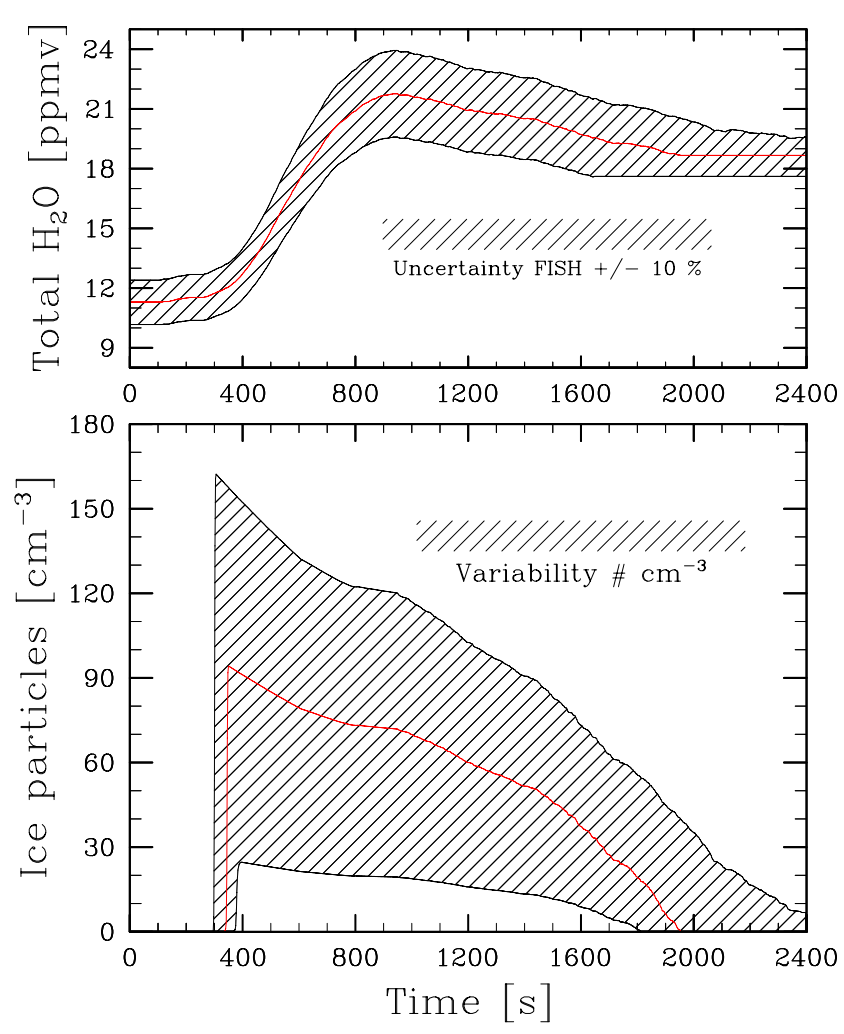

Fig. 12. Variation of the modeled ice number density caused by imposed shifts of the FISH data by $\pm 10 \%$. The red line indicates the baseline model run discussed in Sect. 4. 

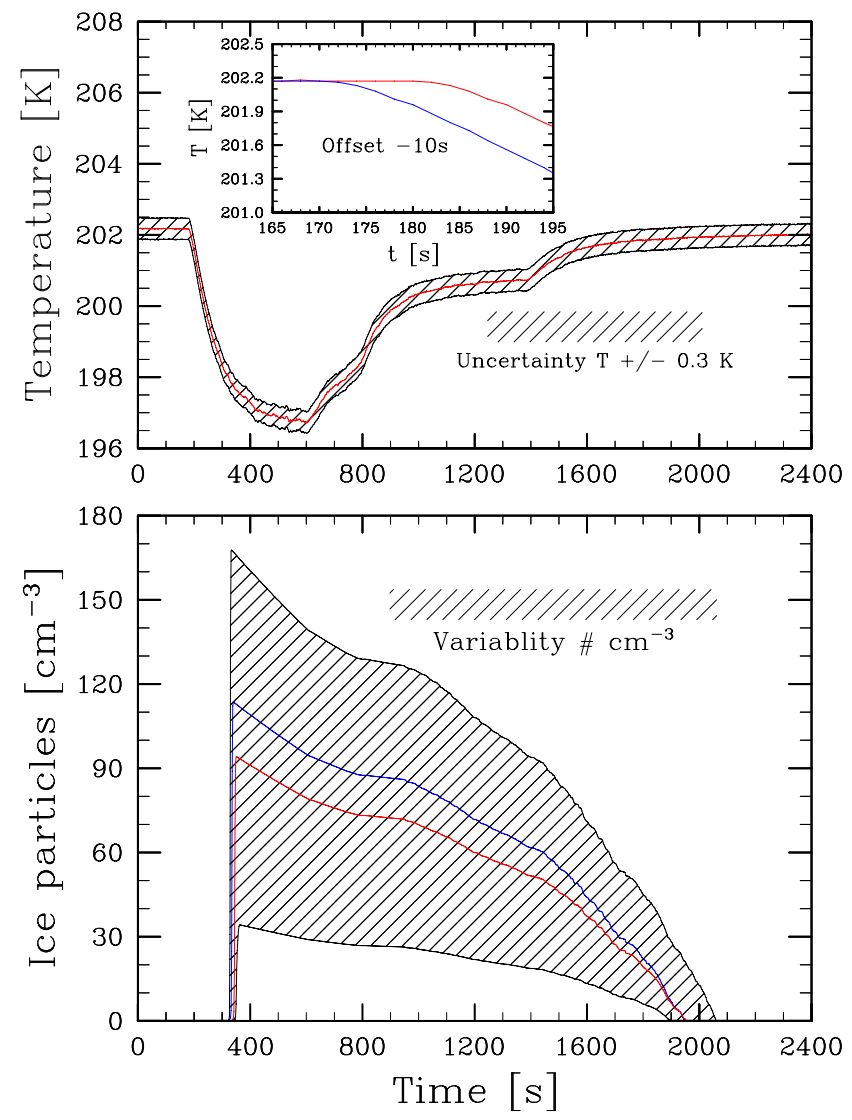

Fig. 13. Variation of the modeled ice number density caused by imposed shifts of the temperature data by $\pm 0.3 \mathrm{~K}$ (top panel) and by a shift of the time axis by $-10 \mathrm{~s}$ (bottom panel). The red curve indicates the baseline model run discussed in Sect. 4; the blue curve representing the shifted profile is not visible on the extended scale in the top panel.

lations with values $10 \%$ higher and lower than the original data, holding all other input parameters constant.

The imposed shifts of the total $\mathrm{H}_{2} \mathrm{O}$ mixing ratio by $\pm 10 \%$ (top panel of Fig. 12) lead to a variability of the total ice number density of $\sim \pm 80 \%$ (bottom panel), slightly more than the experimental uncertainty of the measurement data (recall the vertical bar in Fig. 7). In the absence of ice particles before the freezing process, higher or lower values of the total water mixing ratio directly increase or decrease the gaseous $\mathrm{H}_{2} \mathrm{O}$ in the simulations. Hence, the threshold value of RHI for homogeneous ice nucleation $\left(\mathrm{RHI}_{n u c}\right)$ is reached earlier or later, as the different freezing onsets in Fig. 12 indicate.

We cannot argue that a higher (lower) total $\mathrm{H}_{2} \mathrm{O}$ mixing ratio consistently increases (decreases) the number of nucleated ice particles. Because of the time shifts of the freezing onset times, the aerosol particles undergo the phase transition at different temperatures and cooling rates. In turn, this leads to shifts in the narrow range between the peak RHI and $\mathrm{RHI}_{\text {nuc }}$. It is the exact combination of $T, d T / d t$ and RHI
Table 2. Sensitivity of simulated ice number density $n$ to variations of the deposition coefficient of AIDA experiment A3_1 with initial temperature $T_{0}=202.2 \mathrm{~K}$

\begin{tabular}{cccccc}
\hline$\alpha$ & 0.05 & 0.1 & 0.2 & 0.5 & 1.0 \\
\hline$n\left[\mathrm{~cm}^{-3}\right]$ & 549 & 278 & 171 & 94 & 61 \\
\hline$n\left(D_{p}>1.5 \mu \mathrm{m}\right)\left[\mathrm{cm}^{-3}\right]$ & 482 & 264 & 168 & 93 & 61 \\
\hline
\end{tabular}

around the time where the ice saturation ratio reaches its peak that controls the total number of ice crystals formed (recall Sect.4.3). For example, in a model run with a FISH value $+2.5 \%$ more ice particles form than in a run with a value $+5 \%$ (not shown in Fig. 12). This again stresses the importance to obtain accurate measurements of $\mathrm{H}_{2} \mathrm{O}$ mixing ratios for modeling cirrus cloud formation in the real atmosphere.

\subsection{Temperature}

In modeling ice formation in the AIDA chamber, we assume that the air volume containing the freezing particles is homogeneously mixed. The typical time scale for mixing of the total volume is of the order of a few seconds, short enough to ensure that this assumption should be valid in most of the cases considered and that the mean gas temperature derived from 4 independent measurements at different locations in the chamber volume is a well-defined quantity.

Vertical inhomogeneities in temperature may occur when very high cooling rates are applied, leading to patches of air that contain lower and higher number densities of crystals (compared to a well mixed situation) that subsequently mix. Temperature fluctuations may become important when the cooling rates are very slow, because mixing rates decrease when the temperature is only weakly varying. As the AIDA sensors measure static temperatures, such fluctuations are not included in the model.

We investigate the sensitivity of our simulations upon uncertainties in temperature in two ways. First, we vary the temperature profile by $\pm 0.3 \mathrm{~K}$ according to the experimental accuracy (see top panel of Fig. 13). Second, we shift the time axis of measured temperature (red curve in the top panel of Fig. 13) by $-10 \mathrm{~s}$, that means we start cooling $10 \mathrm{~s}$ earlier (see the zoom of temperature inside Fig. 13, blue curve) without a concomitant shift of the air and $\mathrm{H}_{2} \mathrm{O}$ pressures. There is an offset in the temperature measurement because the temperature sensors do not react instantenously to temperature changes. This offset increases from $-3 \mathrm{~s}$ at $1000 \mathrm{hPa}$ to $-10 \mathrm{~s}$ at $180 \mathrm{hPa}$.

The imposed temperature shift results in a variability of the ice number density that is within the range of ice particle concentrations caused by the shifts of the FISH data or caused by the temperature uncertainty itself (bottom panel of Fig. 13). 


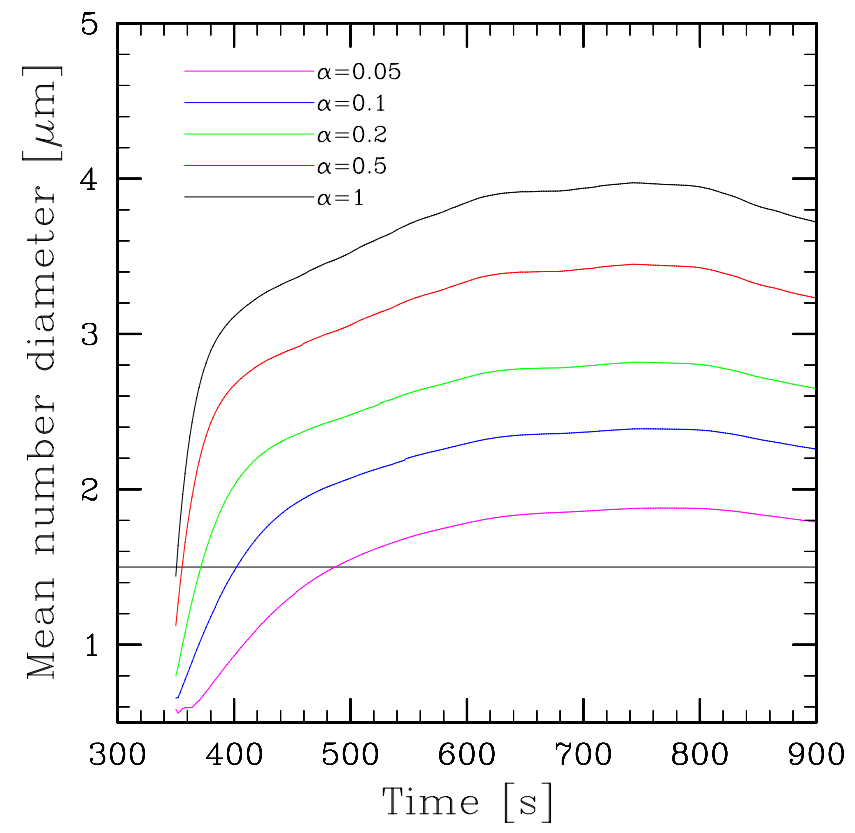

Fig. 14. Modeled temporal evolution of the mean number diameter of ice particles for different assumptions of the water vapor deposition coefficent on ice $\alpha$, as indicated by the legend. Nucleation takes place when the curves start, and the peak number densities are observed in the AIDA chamber at times between $600 \mathrm{~s}$ and $900 \mathrm{~s}$ (see black curve in Fig. 7, right panel). The solid line marks the counting limit $1.5 \mu \mathrm{m}$ for ice particles measured with the optical particle counter.

\subsection{Deposition coefficient}

The deposition coefficient $\alpha$ of water molecules onto the ice particles enters the effective diffusion rate of $\mathrm{H}_{2} \mathrm{O}$ molecules (Pruppacher and Klett, 1997). The mass growth rate in the kinetic regime is directly proportional to $\alpha$, while the rate is independent of it in the diffusion regime. In the upper troposphere, the kinetic regime typically applies for submicrometer-sized particles. Small values of $\alpha$ slow the initial mass growth rate of the freshly formed ice crystals.

A reduction of the initial growth rate allows more ice particles to be formed under otherwise unchanged conditions, because the $\mathrm{H}_{2} \mathrm{O}$ vapor concentration stays elevated for a slightly longer time (Kärcher, 2002). As discussed with the help of Fig. 8, the mean number radius $r$ of the ice particles up to $350 \mathrm{~s}$ is $\sim 0.5 \mu \mathrm{m}$. The characteristic radius controlling the transition between kinetic and diffusive regime is given by $4 \lambda / 3 \alpha \simeq 1.4 \mu \mathrm{m}$, with the mean free path $\lambda=0.53 \mu \mathrm{m}$ (Sect. 4.5). This radius is comparable to the nascent ice particle radii, thus we can expect a sensitivity of our results upon variations of $\alpha$.

The value $\alpha=0.5$ is used for the baseline runs. Table 2 (second row) shows the modeled total ice number density $n$ for the baseline experiment under the assumption of different values of $\alpha$. As expected, the total number of nucleated ice
Table 3. Sensitivity of simulated ice number density of AIDA experiment A3_1 $\left(T_{0}=202.2 \mathrm{~K}\right)$ to variations of the geometric standard deviation $\sigma$ of the initial aerosol size distribution

\begin{tabular}{ccccc}
\hline$\sigma$ & 1.3 & 1.5 & 1.75 & 2.0 \\
\hline$n\left[\mathrm{~cm}^{-3}\right]$ & 74 & 53 & 94 & 74 \\
\hline
\end{tabular}

particles increases as $\alpha$ decreases, and the rise of $n$ becomes pronounced (the baseline value changes by more than a factor of 2) for values $\alpha<0.2$. For higher values, the sensitivity is much less pronounced. This is consistent with results from other studies (Lin et al., 2002).

The same trend is observed when we study the number densities of ice particles with diameters greater than $1.5 \mu \mathrm{m}$ as a function of $\alpha$ (third row in Table 2), although the concentrations become smaller than the total concentrations when $\alpha$ decreases. As $\alpha$ is lowered, the mean ice particle size decreases as the same amount of water vapor is distributed among a larger number of particles. This is highlighted in Fig. 14 where we show the mean number diameters of ice particles versus time for various $\alpha$ from the APSC. The initial reduction of the mean size delays the detection of ice particles with diameters above the counting limit of $1.5 \mu \mathrm{m}$ of the optical particle counter (solid line in Fig. 14). However, even in the case $\alpha=0.05$ the bulk of the ice particles grow above this limit shortly after nucleation.

Comparing Table 2 with Table 1, we conclude that changes of $\alpha$ within the range $0.2 \cdots 1$ suffice to obtain better fits to the observed ice number densities, if $\alpha$ is considered to be the only uncertain parameter. We have ran the baseline case with $\alpha=0.05$ and found no combination of $T$ and total $\mathrm{H}_{2} \mathrm{O}$ within their uncertainty limits that predicted the number of ice particles consistent with the measurements. Thus, the use of values significantly below 0.2 is not supported by this analysis.

\subsection{Aerosol size distribution}

With regard to the number of nucleated ice particles, aerosol size effects become important when the time scale of the nucleation event is fast compared to the time scale of depositional growth of the pristine ice particles (Kärcher and Lohmann, 2002). Figure 8 indicates slow growth and rapid freezing for the case study in Sect. 4 and therefore aerosol size effects are important in our simulations. This also holds for the other cases summarized in Table 1.

We investigate the influence of the initial aerosol size distribution on the number of nucleated ice particles by a variation of the geometric standard deviation $\sigma$ (recall Fig. 3). The results are shown in Table 3. The value of $\sigma=1.75$ is used in the baseline simulations. Broader or narrower size distributions lead to variations of the ice number density smaller than its experimental uncertainty, indicating a limited sensitivity 
of our simulations on the aerosol size distribution compared to temperature and humidity uncertainties, in agreement with theory (Kärcher and Lohmann, 2002).

\section{Conclusions}

Calculated threshold relative humidities for homogeneous ice nucleation, total ice particle number densities, and times of the onset of freezing agree well with the experimental data, provided the calculations are driven by observed temperature and pressure profiles and take into account water vapor and heat fluxes from the chamber walls. A detailed discussion of a case study, including the evolution of the freezing particles and the partitioning of water between gas, aerosol, and ice phase, elucidated the microphysical processes at work during cooling and freezing in the AIDA chamber.

A series of sensitivity studies has shown that the number of ice crystals formed is highly sensitive to variations of the temperature and the total water content, and thus relative humidity. In comparison, variations of the initial aerosol spectrum have only a limited influence on the calculated properties of the pristine ice particles. The use of values significantly below 0.2 for the water vapor deposition coefficient on ice is not supported by this analysis.

The freezing studies carried out in the AIDA chamber approximate real cirrus cloud formation in the atmosphere and provide stringent tests of numerical models to simulate these processes. The good agreement between measurements and model results demonstrates that the activity parameterization of homogeneous freezing rates in supercooled $\mathrm{H}_{2} \mathrm{SO}_{4} / \mathrm{H}_{2} \mathrm{O}$ solutions provided by Koop et al. (2000) can be safely employed to simulate the formation of ice crystals in cirrus clouds by this process.

We believe that the use of smaller cooling rates would not alter this statement, although we could not test this aspect here because significantly smaller cooling rates cannot be achieved with the current experimental set up. Inasmuch the results of Koop et al. (2000) can be used to describe homogeneous freezing in other types of liquid supercooled aerosols (e.g., ternary $\mathrm{H}_{2} \mathrm{O} / \mathrm{H}_{2} \mathrm{SO}_{4} / \mathrm{HNO}_{3}$ particles), we believe that the above statement holds for such other types of liquid particles as well. Of course, we do not rule out the possibility of heterogeneous freezing in the atmosphere.

The threshold values of relative humidity for homogeneous freezing given by Koop et al. (2000), however, may not exactly hold when applied to atmospheric conditions, as enhanced supersaturations and non-equilibrium compositions of the largest liquid particles caused by rapid cooling and low temperatures can lead to somewhat higher values than determined assuming equilibrium conditions.

Acknowledgements. This research was conducted, in part, within the project "Particles in the Upper Troposphere and Lower Stratosphere and Their Role in the Climate System" (PARTS) funded by the European Commission within the Fifth Framework Program and contributes to the project "Particles and Cirrus Clouds" (PAZI) funded by the Helmholtz-Gemeinschaft Deutscher Forschungszentren (HGF). The contribution from Forschungszentrum Karlsruhe was funded by BMBF (AFO 2000, project POSTA) and by the European Commission (FP 5, project CIPA). We thank Konrad Mauersberger and his team for fruitful discussions during the project meetings. We thank Paul DeMott and an anonymous reviewer for constructive interactive discussions of this work.

\section{References}

Bertram, A. K., Koop, T., Molina, L. T., and Molina, M. J.: Ice formation in $\left(\mathrm{NH}_{4}\right)_{2} \mathrm{SO}_{4}-\mathrm{H}_{2} \mathrm{O}$ particles, J. Phys. Chem., 104, 584-588, 2000.

Carslaw, K. S., Peter, Th., and Clegg, S. L.: Modeling the composition of liquid stratospheric aerosols, Rev. Geophys., 35, 125-154, 1997.

Chang, H.-Y. A., Koop, T., Molina, L. T., and Molina, M. J.: Phase transitions in emulsified $\mathrm{HNO}_{3} / \mathrm{H}_{2} \mathrm{O}$ and $\mathrm{HNO}_{3} / \mathrm{H}_{2} \mathrm{SO}_{4} / \mathrm{H}_{2} \mathrm{O}$ solutions, J. Phys. Chem. A, 103, 2673-2679, 1999.

Chen, Y., DeMott, P. J., Kreidenweis, S. M., Rogers, D. C., and Sherman, D. E.: Ice formation in sulfate and sulfuric acid aerosol particles under upper tropospheric conditions, J. Atmos. Sci., 57, 3752-3766, 2000.

Field, P. R., Cotton, R. J., Noone, K., Glantz, P., Kaye, P. H., Hirst, E., Greenaway, R. S., Jost, C., Gabriel, R., Reiner, T., Andreae, M., Saunders, C. P. R., Archer, A., Choularton, T., Smith, M., Brooks, B., Hoell, C., Bandy, B., Johnson, D., and Heymsfield, A.: Ice nucleation in orographic wave clouds: Measurements made during INTACC, Q. J. R. Meteorol. Soc., 127, 1493-1512, 2001.

Haynes, D. R., Tro, N. J., and George, S. M.: Condensation and evaporation of $\mathrm{H}_{2} \mathrm{O}$ on ice surfaces, J. Phys. Chem., 96, 8502-8509, 1992.

Heymsfield, A. J. and Sabin, R. M.: Cirrus crystal nucleation by homogeneous freezing of solution droplets, J. Atmos. Sci., 46, 2252-2264, 1989.

Heymsfield, A. J. and Miloshevich, L. M.: Homogeneous ice nucleation and supercooled liquid water in orographic wave clouds, J. Atmos. Sci., 50, 2335-2353, 1993.

Heymsfield, A. J. and Miloshevich, L. M.: Relative humidity and temperature influences on cirrus formation and evolution: Observations from wave clouds and FIRE II, J. Atmos. Sci., 52, 43024326, 1995.

Jacobson, M.Z.: Fundamentals of Atmospheric Modeling, Cambridge Univ. Press, Cambridge, U. K., 1999.

Jensen, E. J. and Toon, O. B.: Homogeneous freezing nucleation of stratospheric solution droplets, Geophys. Res. Lett., 18, 18571860, 1991.

Jensen, E. J. and Toon, O. B.: The potential effects of volcanic aerosols on cirrus cloud microphysics, Geophys. Res. Lett., 19, 1759-1762, 1992.

Jensen, E. J., Toon, O. B., Tabazadeh, A., Sachse, G. W., Anderson, B. E., Chan, K. R., Twohy, C. W., Gandrud, B., Aulenbach, S. M., Heymsfield, A. J., Hallett, J., and Gary, B.: Ice nucleation processes in upper tropospheric wave-clouds observed during SUCCESS, Geophys. Res. Lett., 25, 1363-1366, 1998.

Kärcher, B.: Properties of subvisible cirrus clouds formed by homogeneous freezing, Atmos. Chem. Phys., 2, 161-170, 2002. 
Kärcher, B. and Lohmann, U.: A parameterization of cirrus cloud formation: Homogeneous freezing including effects of aerosol size, J. Geophys. Res., 107 (D23), 4698, doi:10.1029/2001JD001429, 2002.

Koop, T., Ng, H. P., Molina, L. T., and Molina, M. J.: A new optical technique to study aerosol phase transitions: The nucleation of ice from $\mathrm{H}_{2} \mathrm{SO}_{4}$ aerosols, J. Phys. Chem. A, 102, 8924-8931, 1998.

Koop, T., Bertram, A. K., Molina, L. T., and Molina, M. J.: Phase transitions in aqueous $\mathrm{NH}_{4} \mathrm{HSO}_{4}$ solutions, J. Phys. Chem. A, 103, 9042-9048, 1999.

Koop, T., Luo, B.P., Tsias, A., and Peter, Th.: Water activity as the determinant for homogeneous ice nucleation in aqueous solutions, Nature, 406, 611-614, 2000.

Lin, H., Noone, K. J., Ström, J., and Heymsfield, A. J.: Small ice crystals in cirrus clouds: A model study and comparison with in situ observations, J. Atmos. Sci., 55, 1928-1939, 1998.

Lin, R.-F., Starr, D. O. C., DeMott, P. J., Cotton, R., Sassen, K., Jensen, E., Kärcher, B., and Liu, X.: Cirrus parcel model comparison project phase 1: The critical components to simulate cirrus initiation explicity, J. Atmos. Sci., 59, 2305-2329, 2002.

Luo, B. P., Carslaw, K. S., Peter, Th., and Clegg, S. L.: Vapour pressures of $\mathrm{H}_{2} \mathrm{SO}_{4} / \mathrm{HNO}_{3} / \mathrm{HCl} / \mathrm{HBr} / \mathrm{H}_{2} \mathrm{O}$ solutions to low stratospheric temperatures, Geophys. Res. Lett., 22, 247-250, 1995.

Möhler, O., Stetzer, O., Schaefers, S., Linke, C., Schnaiter, M., Tiede, R., Saathoff, H., Krämer, M., Mangold, A., Budz, P.,
Zink, P., Schreiner, J., Mauersberger, K., Haag, W., Kärcher, B., and Schurath, U.: Experimental investigations of homogeneous freezing of sulphuric acid particles in the aerosol chamber AIDA, Atmos. Chem. Phys., 3, 3, 211-223, 2003.

Peter, Th.: Microphysics and heterogeneous chemistry of polar stratospheric clouds, Annu. Rev. Phys. Chem., 48, 785-822, 1997.

Pruppacher, H. R. and Klett, J. D.: Microphysics of Clouds and Precipitation, Kluwer Acad. Pub., Dordrecht, 1997.

Sassen, K. and Dodd, G. C.: Haze particle nucleation simulation in cirrus clouds and application for numerical and lidar studies, J. Appl. Sci., 46, 3005-3014, 1989.

Tabazadeh, A., Jensen, E. J., and Toon, O. B.: A model description for cirrus cloud nucleation from homogeneous freezing of sulfate aerosols, J. Geophys. Res., 102, 23 845-23 850, 1997.

Tabazadeh, A., Martin, S. T., and Lin, J.-S.: The effect of particle size and nitric acid uptake on the homogeneous freezing of aqueous sulfuric acid particles, Geophys. Res. Lett., 27, 1111-1114, 2000.

Zöger, M., Afchine, A., Eicke, N., Gerhards, M.-T., Klein, E., McKenna, D. S., Mörschel, U., Schmidt, U., Tan, V., Tuitjer, F., Woyke, T., and Schiller, C.: Fast in situ stratospheric hygrometers: A new family of balloon-borne and airborne Lyman- $\alpha$ photofragment fluorescence hygrometers, J. Geophys. Res., 104, 1807-1816, 1999. 